\title{
EDITORIAL
}

\section{Nature as organic chemist}

\author{
The Journal of Antibiotics (2016) 69, 473-485; doi:10.1038/ja.2016.55
}

$\mathrm{B}_{\mathrm{o}}^{\mathrm{y}}$ the time I entered Harvard College in the fall of 1962, I knew, or thought I knew, that I wanted to become a scientist. In fact, I had very little idea what that actually meant, nor did I even know what branch of science to choose. My interest in chemistry was quickly kindled, however, by Prof Leonard K Nash's introductory course in general chemistry. I was not only smitten by the subject itself but also I was inspired by Prof Nash's informative and entertaining lectures, and his warm and scintillating personality. Indeed for many years thereafter, Prof Nash continued to be a source of encouragement and advice on both science and the art of teaching.

My introduction to research came in the spring semester of my second year of college when Prof James Deyrup, who ran the laboratory portion of Prof Louis Fieser's organic chemistry course, invited a dozen students to participate in a special research section in place of the traditional laboratory course in qualitative organic analysis. Although this meant that I never learned (nor particularly cared) what a positive Hinsburg test was, Prof Deyrup introduced us to modern instrumental methods of analysis, including proton NMR, IR and UV spectroscopy, and mass spectrometry. He also taught us how to search for information in Chemical Abstracts and Beilstein. None of these topics was even vaguely addressed by the standard organic chemistry textbook or classroom lectures. Each of us had our own research project, and I spent a substantial proportion of my days and evenings setting up reactions, running chromatography columns and recording my own NMR and IR spectra. Subsequently, I carried out undergraduate research in the laboratory of Prof Paul Dowd, where I first worked on a synthesis of tetrahedrane (unsuccessful) and then, with much effort, tested and ultimately disproved a superficially clever alternative to the acyl enzyme mechanism for chymotrypsincatalyzed hydrolysis that in retrospect turned out to have been biochemically naive.

\section{GRADUATE AND POSTDOCTORAL STUDIES}

In choosing a graduate school, I made the somewhat nonconventional decision to remain in the Harvard Chemistry Department. One attraction was that I would be able to start my $\mathrm{PhD}$ research right away, having already taken all the graduate courses in organic chemistry that Harvard offered. What sealed the deal, however, was the far more salient fact that continuing at Harvard allowed me to remain in Cambridge, not far from Wellesley College where my fiancée was enrolled. That turned out to have been the right decision, and Suzanne and I have now been happily married for nearly 49 years.

In the fall of 1966, I joined the research group of Prof EJ Corey. Although one of the projects proposed to me by Prof Corey involved studying the biological conversion of squalene oxide to lanosterol, I was at that time more interested in the development of new synthetic methods. Over the next few years, I carried out research on a number of novel organolithium reagents, and eventually took up the synthesis of the bicyclic sesquiterpene $\beta$-trans-bergamotene (1), the structure of which had been assigned to a constituent of valerian root oil (Figure 1). ${ }^{1}$ I finally completed my synthesis late one night in February 1971. At 3:00 AM that morning I ran down to the NMR room to record my triumph, only to be stunned when the $60 \mathrm{MHz}{ }^{1} \mathrm{H}$ NMR spectrum of my synthetic $\beta$-trans-bergamotene was found to differ substantially from that reported for the valerian root oil sesquiterpene. ${ }^{2}$ I went home in disgust, but after a few hours sleep I decided that disproving the assigned structure was actually a much more interesting result!

Research in the Corey laboratory spanned a remarkable range of cutting-edge topics. In addition to sterol biosynthesis, there were projects involving phosphorus- and sulfur-stabilized carbanions as well as the development of organocuprate, organonickel and organoaluminum reagents, and new methods for the stereospecific synthesis of trisubstituted olefins. Each method was intended to solve specific challenges in the total synthesis of prostaglandins, sesquiterpenes, and diterpenes then underway in the Corey laboratory. One could therefore learn a tremendous amount of modern organic chemistry just by going around the laboratory and talking to each of the 20 or so graduate students and postdocs about their research.

My interest in the biological origins of natural products was first sparked in 1968 and 1969 by a remarkable series of papers on indole alkaloid biosynthesis from the laboratories of Duilio Arigoni (Eidgenössische Technische Hochschule (ETH), Zürich), 3,4 Alan Battersby, (then at the University of Liverpool) (5, $^{5}$ and Ian Scott (Yale). ${ }^{7}$ Working independently, these investigators had begun to unravel the intricate details of how the simple acyclic monoterpene, geraniol, could serve as the universal precursor of the complex $\mathrm{C}_{9}$ or $\mathrm{C}_{10}$ units of hundreds of distinct alkaloids through the intermediacy of the monoterpene glycoside loganin (Figure 2). I was struck by the elegance of this combination of synthetic organic chemistry and penetrating mechanistic analysis and its power to unravel complex biosynthetic problems. This was clearly high level chemical puzzle solving that was opening a unique window onto nature's chemistry.

By good fortune, Prof Arigoni was a Visiting Professor at Harvard in the spring of 1969 and gave a series of invited lectures on his research on terpene biosynthesis, much of it still unpublished to this day. I arranged to discuss with him the research that was then underway in his laboratory and eventually I joined his group at the ETH as a postdoc. 


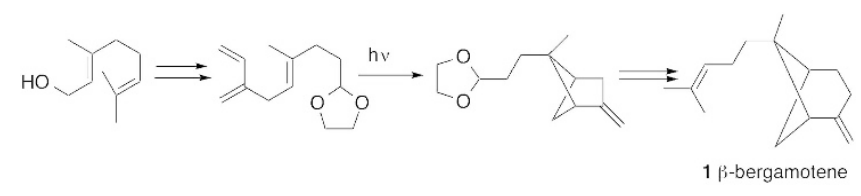

Figure 1 Synthesis of $\beta$-trans-bergamotene (1).

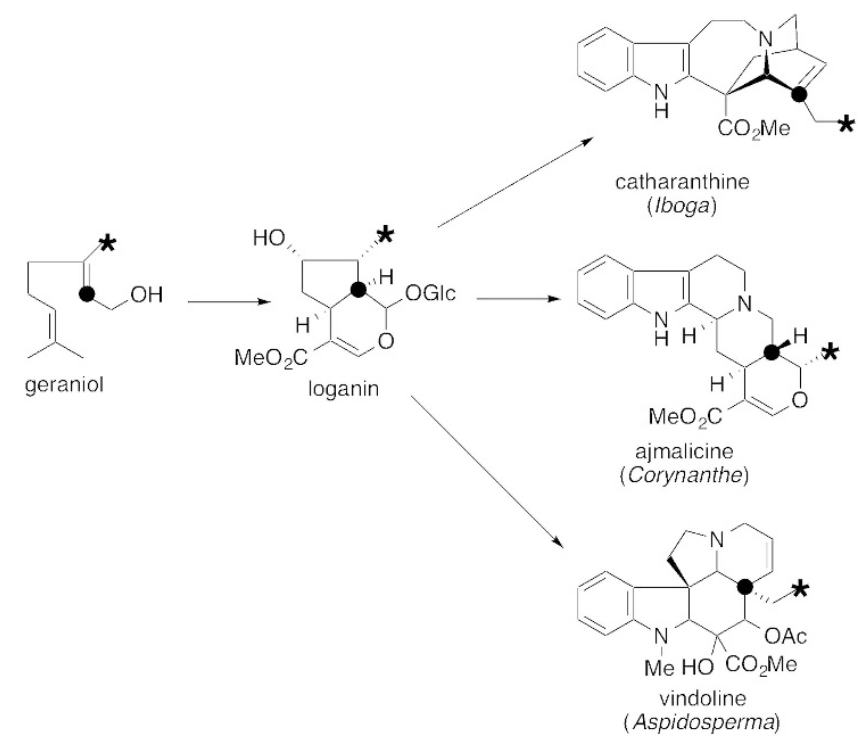

Figure 2 Biosynthesis of $\mathrm{C}_{10}$ unit of indole alkaloids from gernaiol and loganin.

Arriving in Zürich in May 1971 with support from a National Institutes of Health (NIH) postdoctoral fellowship, I took up a study of the biosynthesis of the lagopodins, a group of sesquiterpenoid fungal metabolites whose structures had recently been determined in the Arigoni laboratory. The cyclization of farnesyl diphosphate (FPP), the universal precursor of all sesquiterpenes, to the parent cuparene skeleton of the lagopodins was predicted to require an unusual 1,4-hydride shift, very similar to that thought to be involved in biosynthesis of the related tricothecane family of fungal mycotoxins. ${ }^{8}$ In the early 1970s, rigorous biosynthetic investigations relied predominantly on the feeding of radioisotopically labeled precursors to fungal cultures or plants, followed by isolation of the resultant labeled natural product and determination of the precise distribution of isotope by systematic chemical degradation. The interpretation of the resultant incorporation data was usually guided by a unifying biosynthetic hypothesis, which did not require detailed knowledge of each of the discrete biochemical events in the overall biosynthetic pathway. The determination of the basic biological building blocks would often be followed by isolation, identification, and reincorporation of key intermediates in order to uncover the details of the biological conversion of simple precursor to complex natural product.

Complementing the investigations of natural product biosynthesis in the Arigoni laboratory were extensive studies of the stereochemistry of enzymatic reactions. I realized that I was embarrassingly ignorant of biochemistry, having neglected to take any courses in the subject. To address this deficiency, as well as my lack of German, I worked my way through a standard German undergraduate Biochemistry textbook and began to read the literature in mechanistic enzymology. Another lacuna in my preparation turned out to be my unfamiliarity with many basic stereochemical terms beyond those in my introductory Organic Chemistry textbook. After several weeks of Arigoni Group meetings at which the terms 'prochiral', 'enantiotopic', 'diastereotopic' and 'homotopic' were constantly being tossed about, I interrupted Prof Arigoni and told him I had no idea what he was talking about. His astonished response was 'Didn't they teach you this at Harvard?' He then devoted a half hour to a lucid exposition of these fundamental stereochemical concepts and their importance to the analysis of reaction mechanisms. This short lesson and the numerous applications that I subsequently encountered in the Arigoni laboratory had a profound influence on my thinking about biochemical transformations.

Many years later I heard a lecture by Prof Kurt Wüthrich of ETH, in which he described an ingenious method for assigning the individual ${ }^{13} \mathrm{C}$ NMR signals of valine methyl groups in ${ }^{13} \mathrm{C}$-enriched proteins, based on their distinct biochemical origins. Afterwards, I told Prof Wüthrich how much I had enjoyed his talk, but cautioned him good naturedly that he should be particularly careful to use the correct term 'diastereotopic' rather than 'prochiral' to distinguish the two valine methyl groups, since this nomenclature had been developed at the ETH, and his colleagues in the Chemistry Department might take exception. In fact, just a few weeks after this conversation, Duilio was reading a review article by Prof Wüthrich and telephoned him to point out that he could not refer to a 'prochiral' methyl group. Wüthrich expressed astonishment and said that he had been using these same terms for years without encountering any argument, until a few weeks before when someone had objected to his stereochemical nomenclature. Duilio immediately interjected 'David Cane, right?' and Wüthrich replied 'How on earth did you know that?' Duilio told me that in just a few short years I had gone from stereochemical neophyte to fanatic proselytizer.

The scientific environment in the Arigoni laboratory and in the ETH Chemistry Department was extraordinarily stimulating. There was great excitement and interest in chemistry and biochemistry of all sorts. Among the faculty, there was an obvious sense of scientific and intellectual camaraderie. At Departmental Colloquia, Prof Vladimir Prelog provided amusing stories, cautionary tales, and insightful commentary on all topics. During morning or afternoon coffee in the Department lunchroom, Prof Prelog frequently held court with graduate students and postdocs. Duilio delighted in energetically debating scientific ideas and discussing the latest chemical advances with both students and faculty colleagues. Group meetings, led by Prof Arigoni in a seamless mix of German, Italian, French and English, focused on solving mechanistic puzzles, analyzing biosynthetic data, or reporting on some interesting new result that he had heard about in his travels. At one long group meeting, he worked through extensive spectroscopic and chemical data in order to deduce the complete structure and stereochemistry of the fungal sesquiterpene antibiotic avocettin. ${ }^{9}$ Afterwards I asked the graduate student working on the project when they had actually arrived at the final structure. He shook his head in wonderment and told me that they had discussed the data only an hour before and, as far as he knew, Prof Arigoni had solved the problem in the course of the group meeting!

Although the chemical research at ETH was at the forefront of the field, the best you could say about the ancient laboratories in the nearly 100-year-old Chemiegebaüde was that they had considerable character. Fume hoods consisted of glass-enclosed 'Kappelle', cabinets with a three-inch diameter vent to the outside, which served mostly to allow frigid air into the laboratory. Work with something truly noxious had to be performed outside on the 'Stinkt Balkon', a bracing experience in the Zürich winter. If you wanted to leave a reaction running overnight, you had to bring everything down to the Nacht Labor and place a note on it, or else a watchman would come by and 
turn off your stirrer, heater, and cooling water. I was mocked at first by many of my Swiss laboratory mates when I used my NIH grant money to buy commercial Pasteur pipettes and tlc plates, rather than fabricate them myself as everyone else did. Not surprisingly, within a few months, these items became available from the Chemistry Stockroom, due to universal demand.

In my second year at ETH, I isolated my first enzyme when I had to prepare HMG-CoA reductase. The 3-day procedure started with a $1-\mathrm{kg}$ slab of fresh moist yeast cake obtained from a local baking supply company. My first encounter with a high-speed centrifuge did not go completely smoothly, however, when I destroyed more than a $\$ 1000$ worth of stainless steel centrifuge bottles by spinning them in the wrong size rotor.

During the winter of 1972, I began applying for academic jobs back in the USA. Although I twice paid my own airfare back to the USA for several interviews, by late spring nothing had yet come through. One university had somehow duplicated my application packet and even rejected me twice. The Brown University Chemistry Department initially turned me down in favor of another applicant, then learned later the same day that they would have a second opening when one of their faculty suddenly announced he was leaving to go to medical school. Finally, in early June 1973, I received an offer of an Assistant Professor position from Brown, which I immediately accepted.

\section{ISOPRENOID AND POLYKETIDE BIOSYNTHESIS}

I arrived in Providence, Rhode Island and began my independent academic career in August 1973. I had a startup package of $\$ 5000$ and an empty laboratory for up to four coworkers. Immediately adjacent to my office, I also had my own research laboratory, in which I worked every day for the next 5 years. My first teaching assignment was to give lectures on glycolysis and coenzyme mechanisms (to which I added a healthy dose of stereochemistry) in the undergraduate Biochemistry course. In the spring semester, I taught introductory Organic Chemistry for the first of dozens of times.

It was evident to me that whatever the power and elegance of the classical radioisotope incorporation and chemical degradation methods involving intact organisms that I had learned at ETH, further progress and deeper understanding of biosynthetic transformations would require the development of fundamentally new experimental approaches. A small number of biosynthetic investigators had already demonstrated that ${ }^{13} \mathrm{C}$ NMR could be used for the direct assignment of the distribution of isotope in labeled metabolites, thereby avoiding labor-intensive chemical degradations. Using ingenious multiplelabeling techniques, the retention, breaking or reorganization of $\mathrm{C}-\mathrm{C}$ bonds could also be traced by analysis of the ${ }^{13} \mathrm{C}-{ }^{13} \mathrm{C}$ coupling

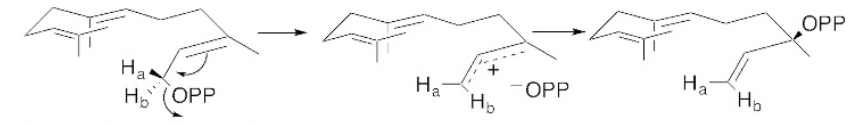

2 farnesyl diphosphate, FPP

3 nerolidyl diphosphate, NPP
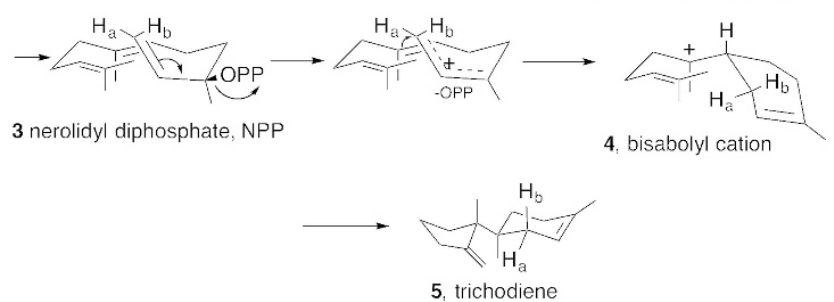

Figure 3 Isomerization of farnesyl diphosphate (2, FPP) to nerolidyl diphosphate (3, NPP) and cyclization of NPP to trichodiene. patterns in the spectra of the labeled products. The other major change in methodology that beckoned was the development of what were at the time simply referred to as 'cell-free systems'. Traditional incorporation experiments were frequently thwarted by poor uptake of precursors by intact cells, resulting in extremely low levels of isotopic labeling in the resultant metabolites. Moreover, the laboriously prepared, isotopically labeled precursors might be degraded by the host organism without ever entering the target biosynthetic pathway. Even when uptake and incorporation were not a problem, labeled biosynthetic intermediates could also lose the isotope of interest during a subsequent biosynthetic step, with concomitant erasure of the desired mechanistic information. By breaking open the host cells before the administration of labeled precursors, the problems of cell permeability might be avoided while honing in on individual biochemical transformations.

My first independent research projects focused on the biosynthesis of isoprenoids and the mechanism of terpene cyclization reactions. Although Leopold Ruzicka's Biogenetic Isoprene Rule had provided a coherent and powerful mechanistic framework for rationalization of the biosynthesis of cyclic terpenes, the model had glossed over the geometric impediment to direct cyclization of the universal precursor trans, trans-farnesyl diphosphate (2, FPP) to give sesquiterpene products harboring cis-double bonds in six- or ten-membered rings. ${ }^{10}$ By 1973, a number of researchers were claiming that the essential geometric isomerization of farnesol involved reversible, nicotinamide-dependent oxidation and reduction, with interconversion of the intervening trans- and cis-farnesal. This process would require the mandatory loss of one of the original C-1 hydrogen atoms of FPP (without even reckoning with the necessity of regenerating the diphosphate ester). I thought that such proposals were based on muddled thinking and even shakier evidence and instead favored a cyclization mechanism involving the initial isomerization of FPP to its tertiary allylic isomer, nerolidyl diphosphate $(3, \mathrm{NPP})$, which would then be the actual substrate to undergo cyclization (Figure 3 ).

I submitted my first research grant proposal dealing with these ideas to the National Science Foundation (NSF) within a month of my arrival at Brown. The application was immediately shunted from the Natural Products Program in the Division of Chemistry, which said that it did not have any funds for new projects, over to the Metabolic Biology Program. Most of the reviews were very positive, but one referee, who was not at all impressed, wrote: 'The applicant is a bright young organic chemist with little or no insight into biological processes. I doubt if he has ever seen a centrifuge.' I resisted the urge to riposte by bringing up the wrecked centrifuge bottles. Fortunately, my NSF Program Officer took a more benign view and my initial grant was funded. With support from this NSF grant and its successors we demonstrated for the first time the mandatory intermediacy of NPP (3) in the cyclization of FPP (2) to the bisabolyl cation (4) and derived sesquiterpenes such as trichodiene (5), without loss of the C-1 hydrogen atoms, thereby definitively excluding all previously proposed redox mechanisms for the trans- to cis-allylic diphosphate isomerization (Figure 3). ${ }^{11,12} \mathrm{We}$ also established that the rearrangement of farnesyl to nerolidyl diphosphate takes place by a net suprafacial 1,3-allylic migration, most likely involving a tight allylic cation-pyrophosphate anion pair. ${ }^{13,14}$

With additional support from the NIH, we also expanded our research program to include the application of ${ }^{13} \mathrm{C}$ NMR to the study of natural product biosynthesis. One of our first projects was an investigation of the biosynthesis of the fungal sesquiterpene ovalicin (6). By incorporation of $\left[3,4-{ }^{13} \mathrm{C}_{2}\right]$ mevalonate we were able to demonstrate that the biosynthesis of ovalicin involves a bond-breaking 
and net-1,3-migration of an eight-carbon isoprenoid side chain (Figure 4). ${ }^{15}$ Steve Buchwald, then a Brown undergraduate and now Professor of Chemistry at MIT, carried out one of the first studies of natural product biosynthesis employing ${ }^{2} \mathrm{H} \mathrm{NMR}$, which he used to establish the incorporation of deuterated mevalonate into ovalicin. ${ }^{16}$ From the fungal mycelium, we also isolated for the first time authentic $\beta$-trans-bergamotene (1), the parent sesquiterpene hydrocarbon in ovalicin biosynthesis, which proved to be identical to the synthetic compound that I had prepared during my $\mathrm{PhD}$ research. ${ }^{17} \mathrm{I}$ could now finally, if only retroactively, claim a total synthesis of a natural product! (Very recently, Prof Yi Tang of UCLA and his group have cloned and characterized the fungal $\beta$-trans-bergamotene synthase involved in the biosynthesis of the closely related metabolite fumagillin. ${ }^{18}$ )

In 1976, we began an investigation of the biosynthesis of pentalenolactone (7), a rearranged sesquiterpene antibiotic produced by a wide variety of Streptomyces species (Figure 5). ${ }^{19,20}$ The project got off to a very slow start, when for more than a year all of our attempts to incorporate simple acetate or mevalonate precursors into pentalenolactone were fruitless. Eventually, I had the idea to feed the Streptomyces culture uniformly labeled $\left[{ }^{13} \mathrm{C}_{6}\right]$ glucose, which I assumed would act as an in vivo precursor of $\left[1,2-{ }^{13} \mathrm{C}_{2}\right]$ acetyl-CoA. In the event we obtained ${ }^{13} \mathrm{C}$-labeled pentalenolactone with a pattern of ${ }^{13} \mathrm{C} \mathrm{NMR}$ signal enhancements and couplings that were nominally consistent with the well-known conversion of acetate to mevalonate and thence to FPP. ${ }^{21}$ The endogenously generated ${ }^{13} \mathrm{C}$-labeled FPP would then be cyclized to the parent tricyclic hydrocarbon pentalenene $(8),{ }^{22}$ which would be converted to pentalenolactone by an unspecified series of oxidation steps. Curiously, the ${ }^{13} \mathrm{C}$ NMR spectrum of the resulting labeled pentalenolactone displayed an additional pair of ${ }^{13} \mathrm{C}-{ }^{13} \mathrm{C}$ couplings that we could not explain at the time. In fact, the origin of these extraneous couplings did not become clear until some 20 years later when the deoxyxylulose phosphate (9, dXP) - methyl eyrthritol phosphate (MEP) pathway to isoprenoids in bacteria and plants was independently discovered by Arigoni ${ }^{23}$ at ETH and Rohmer ${ }^{24}$ at the University of Strasbourg. As is now clear, the conversion of $\left[{ }^{13} \mathrm{C}_{6}\right]$ glucose to FPP by the MEP pathway which operates in Streptomyces ${ }^{25}$ coincidentally gives an identical pattern of ${ }^{13} \mathrm{C}$ enrichments and couplings as would the classical mevalonate pathway. Only upon the 1,2-migration of one of the geminal methyl groups of pentalenolactone does the extra coupling become evident for a dXP-MEP-derived metabolite. The biosynthesis of pentalenolactone from 1-deoxyxylulose was directly confirmed by the Arigoni laboratory in $1998 .{ }^{26}$ In retrospect, one might say that we initially deduced the correct biosynthetic pathway for pentalenolactone based (at least in part) on the wrong reasons. This example provides a cautionary lesson on the hidden pitfalls of reasoning by biosynthetic analogy: always make sure that you have chosen the correct analogy!

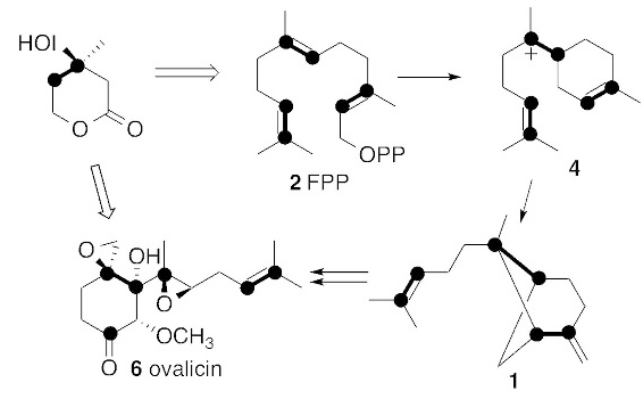

Figure 4 Biosynthesis of ovalicin (6).
As our studies of isoprenoid biosynthesis progressed, we began to focus on the isolation and characterization of the enzymes responsible for the cyclization of FPP to the parent sesquiterpene hydrocarbons and alcohols. We succeeded in obtaining active, although initially very crude, preparations of several such microbial sesquiterpene cyclases, including trichodiene (5), pentalenene $(\mathbf{8}),{ }^{27,28}$ aristolochene $(\mathbf{1 0})^{29,30}$ and bergamotene (1) synthases, ${ }^{31}$ which we used to investigate the detailed mechanism and stereochemistry of the cyclization of FPP (Figure 6). For example, Hyun-Joon $\mathrm{Ha}$, then a graduate student in my laboratory and now Professor of Chemistry at Hankuk University of Foreign Studies in Seoul, Korea, established the intermediacy of nerolidyl diphosphate (3) in the cyclization of FPP (2) to trichodiene (5), and worked out the full stereochemical details of the trichodiene synthase-catalyzed isomerization-cyclization sequence (Figure 3). ${ }^{11,12}$

In the meantime, I had been following with keen interest the work of Rod Croteau at Washington State University on monoterpene biosynthesis and the enzymatic cyclization of geranyl diphosphate (11, GPP) by enzyme preparations obtained from common herbs such as sage, mint and fennel, all prolific producers of terpenoid essential oils. $^{32-34}$ The technical expertise and intellectual rigor of the Croteau papers had already brought long-awaited intellectual order and mechanistic clarity to the study of monoterpene biosynthesis. With the strong encouragement of Prof Arigoni, in the summer of 1980 I called Rod, whom I had not yet met, described some of my ideas to him, and proposed that we collaborate, to which Rod generously agreed. We began our work together by examining the enzymatic cyclization of $\left[1-{ }^{18} \mathrm{O}\right] \mathrm{GPP}(11)$ to bornyl diphosphate (12, BPP), using partially purified enzyme preparations from sage and tansy (Figure 7). These studies led to the unexpected discovery that the $(+)$ - and $(-)$ BPP synthases tightly restrict the internal motion of the transiently generated inorganic pyrophosphate ion during the isomerization of GPP to (-) or (+) linalyl diphosphate (13, LPP) followed by cyclization to BPP, with exclusive recapture of the original pyrophosphate ester oxygen by the bornyl cation..$^{35,36}$ I have described elsewhere the behind-the-scenes, somewhat chaotic ups and downs that enlivened this early work. ${ }^{37}$ The BPP synthase project was the beginning of an intensive, nearly ten-year collaboration, as well as the development of a close personal friendship, that led us together to formulate and experimentally verify a general mechanistic and stereochemical model for the isomerization-cyclization of GPP to cyclic monoterpenes. ${ }^{38}$

Back in the summer of 1974, I had attended the IUPAC Natural Products Symposium at Carleton University in Ottawa where I met three other young American chemists who were beginning their work in the field of natural product biosynthesis. Dick Hutchinson at the University of Wisconsin and Ron Parry at Brandeis had both recently been postdocs in Prof Alan Battersby's laboratory in Cambridge. Steve Gould, whom I already knew from our time together as postdocs in Arigoni's laboratory, was just starting out at the University of Connecticut. For the four of us, who found that we had many scientific interests in common, this was the beginning of mutual friendships and multiple scientific interactions that spanned the next three decades.

In September of that same year, I also attended the American Chemical Society national meeting in Atlantic City. This was before casinos came to Atlantic City and the once fashionable hotels were rundown and shabby, with only a hint of their former grandeur. One afternoon, Prof Arigoni and I discussed science as we strolled along the boardwalk, stopping from time to time to play the pinball machines. He suggested in an offhand way that I might want to look 


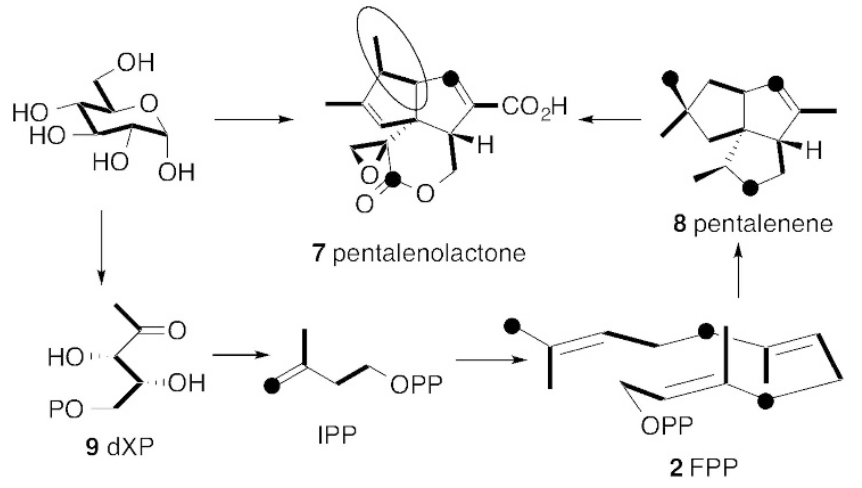

Figure 5 Conversion of $\left[\mathrm{UL}^{13}{ }^{13} \mathrm{C}_{6}\right]$ glucose to pentalenolactone (7) via the dXP-MEP pathway to IPP and FPP, cyclization of FPP to pentalenene (8) and oxidative conversion to $\mathbf{8}$ to pentalenolactone.

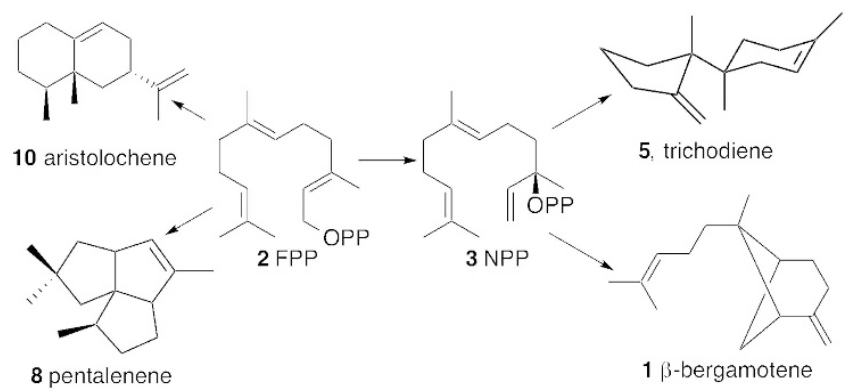

Figure 6 Enzyme-catalyzed formation of sesquiterpenes by cyclization of FPP.

into the biosynthesis of macrolides, which he said appeared to have a number of intriguing features. Although the complexity and reactivity of the macrolide antibiotics and the consequent paucity of workable chemical degradation reactions had thwarted the application of classical radioactive labeling methods, the field was experiencing a burst of new interest with the recent advances in stable isotope labeling and analysis by ${ }^{13} \mathrm{C}$ NMR. By the mid 1970s, however, most investigations of macrolide biosynthesis had still largely been limited to identification of the acetate and propionate building blocks, results that provided valuable support for the basic biosynthetic schemes but gave little insight into how these chemically and stereochemically complex polyketide backbones were actually assembled.

Dr Walter Celmer, whose team at Pfizer had a major role in the isolation and structure elucidation of numerous antibiotics, had proposed a general stereochemical model of macrolide structure, pointing out that all macrolides, whether harboring a core 12-, 14- or 16-membered ring, displayed a common pattern of chemical functionality and stereochemistry that was either identical or closely related to the structure of 6-deoxyerythronolide B, the parent macrolide aglycone of the erythromycin family of antibiotics. ${ }^{39,40}$ Although the Celmer Model was largely an exercise in comparative chemical anatomy that was intended primarily as a guide to structure determination, it clearly had profound biosynthetic implications. The absence of any obvious stereochemical regularity in the configuration of the various methyl and hydroxyl substituents along the macrolide backbone made it evident that the assembly of the parent polyketide chain must involve a complex level of programming for which there was no clear biochemical precedent. Moreover, whatever the mechanistic basis for this chemical complexity, the generality of the Celmer Model suggested that all members of the macrolide family

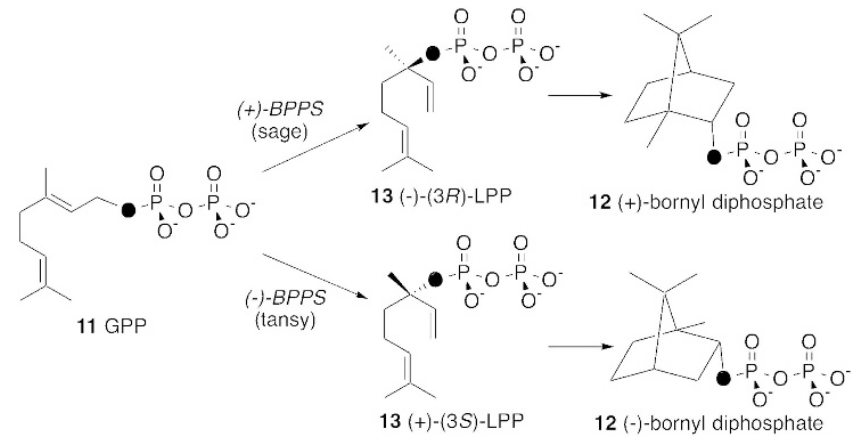

Figure 7 Cyclization of [1-180]GPP to $(+)$ and $(-)$ bornyl diphosphate.

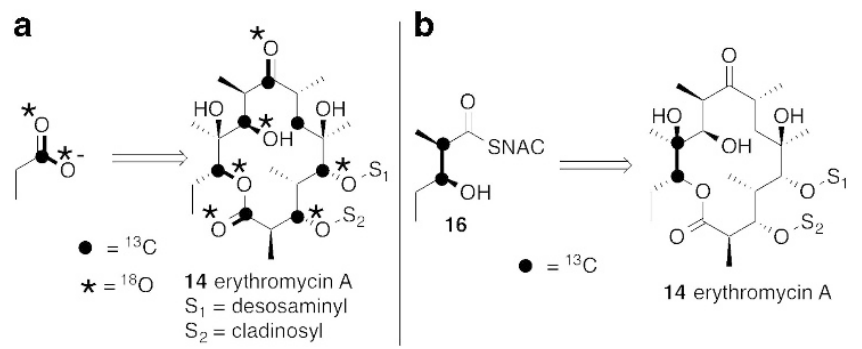

Figure 8 Biosynthesis of erythromycin A (14). (a) Incorporation of $\left[1-{ }^{13} \mathrm{C}\right.$, $1^{18} \mathrm{O}_{2}$ ]propionate by Saccharopolyspora erythraea and origin of the macrolide oxygen atoms of 14 . (b) Intact incorporation of a diketide-SNAC intermediate 16 into 14 .

must be assembled by variations of the same fundamental biochemical program. Thus by studying the biosynthesis of a specific member of the macrolide family one would in effect be studying the biosynthesis of macrolides in general.

We began our research on macrolide biosynthesis by determining the origins of the macrolide oxygen atoms in erythromycin (14) by incorporation of $\left[1-{ }^{13} \mathrm{C},{ }^{18} \mathrm{O}_{2}\right]$ propionate, using the recently discovered ${ }^{18} \mathrm{O}$ isotope effects on ${ }^{13} \mathrm{C}$ chemical shifts to assign the sites of oxygen labeling (Figure $8 \mathrm{a}) .{ }^{41}$ We then extended these finding by determining the origins of oxygen atoms of the antibiotic nargenicin ${ }^{42,43}$ and the anti-helminthic agent avermectin. ${ }^{44}$ Turning to polyether antibiotics, we also established the derivation of all the oxygens in monensin (15) and the closely related lenoremycin from acetate, propionate or molecular oxygen (Figure 9). ${ }^{45,46}$ On the basis of these latter discoveries, we extended an original suggestion of Dr John Westley of Hoffman-La Roche for the biosynthesis of lasalocids and proposed a general stereochemical model of polyether biosynthesis, involving the nucleophilic cascade cyclization of polyepoxide intermediates derived from an initially formed all-E-unsaturated polyketide (Figure 9) ${ }^{47}$ In recent years, this biosynthetic hypothesis has been strongly validated by an array of independent molecular genetic, biochemical, and structural biological studies by Prof Peter Leadlay ${ }^{48,49}$ at the University of Cambridge and Prof Hideaki Oikawa ${ }^{50,51}$ at the University of Hokkaido.

Having established that all the oxygen atoms of 6-deoxyerythronolide B are derived from the carboxyl oxygens of the propionate precursor, we then asked at what stage the oxidation level and stereochemistry of each site would be fixed, whether during construction of the parent polyketide or after assembly of a full-length, unreduced poly- $\beta$-ketoheptaketide. Intact incorporation of the $\mathrm{N}$-acetylcysteamine thioester of the $\left[2,3-{ }^{13} \mathrm{C}_{2}\right]-2$-methyl-3-hydroxy 


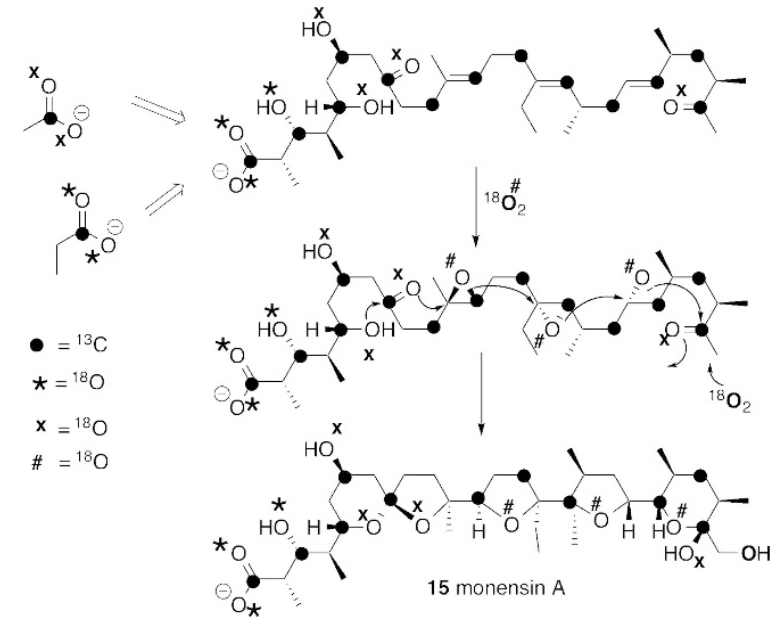

Figure 9 Origin of the oxygen atoms of monensin A (15) and polyepoxide cyclization model for polyether biosynthesis.

diketide substrate (16) established that the oxidation level and stereochemistry of the growing polyketide chain was set during each successive round of chain elongation and that polyketide biosynthesis was therefore processive (Figure $8 \mathrm{~b}$ ). ${ }^{52}$ Hutchinson $^{53}$ independently conceived of the same approach for studying the biosynthesis of the 16-membered ring macrolide aglycone tylactone. We therefore arranged to publish our two sets of results as back-to-back communications. Over the next several years we extended these initial findings and successfully incorporated diketide, triketide, and up to pentaketide intermediates into a wide range of polyketide metabolites. ${ }^{54-56}$

\section{THE US-JAPAN SEMINARS ON THE BIOSYNTHESIS OF NATURAL PRODUCTS}

When I had started at Brown in 1973-1974, I soon realized that although I already knew many of the leading biosynthetic researchers in USA and in Europe, I had not met any of the many active Japanese scientists who were publishing first-rate papers in this area. I was particularly interested in the work of Prof Haruo Seto of the University of Tokyo who, along with his colleague Dr Masato Tanabe of Stanford Research Institute, had recently introduced the use of $\left[1,2-{ }^{13} \mathrm{C}_{2}\right]$ acetate as a biosynthetic precursor of both terpenes and polyketides. ${ }^{57,58} \mathrm{I}$ was also closely following the pioneering publications of Prof Shigeo Nozoe of Tohoku University, who was studying fungal terpenoid biosynthesis using cell-free enzyme systems. ${ }^{59-62}$ With the encouragement of Prof Koji Nakanishi of Columbia University, I therefore wrote to Prof Nozoe and proposed that we organize a small meeting of American and Japanese scientists working in the field of natural product biosynthesis. He readily agreed, and the first US-Japan Seminar on the Biosynthesis of Natural Products, sponsored by the NSF and the Japan Society for the Promotion of Science (JSPS) was held at the East-West Center in Honolulu, Hawaii in June 1976, bringing together about 20 American, Canadian and Japanese scientists working on a wide range of frontier biosynthetic problems. Among the topics of the first meeting were the application of stable isotope NMR to the study of biosynthetic transformations, the development of cell-free biosynthetic systems, and-a particular strength in Japan - the use of plant tissue culture methods to study natural product biosynthesis. Information and results were freely shared among all the participants, and many warm friendships were begun that have continued to this day.
On the basis of the success of this first joint meeting, Prof Ushio Sankawa of the University of Tokyo and I then organized a second US-Japan Biosynthesis Seminar, which again took place in Hawaii in September 1982. The number of participants was modestly expanded, reflecting the growing number of first rank biosynthetic investigators in both countries. The US contingent now included Rod Croteau, Dale Poulter of the University of Utah, Craig Townsend of Johns Hopkins, and Heinz Floss, then at Ohio State University. Besides stable isotope NMR methods and the development of cell-free systems, we also heard about the promise of newly emerging molecular biological methods in talks by Dick Hutchinson and by Dr Tanaka from Prof Satoshi Ōmura's group at Kitasato Institute. In June 1985, John Vederas of the University of Alberta organized a third US-CanadaJapan Biosynthesis Seminar in Banff, Alberta that also included several European and South African researchers.

The first joint US-Japan Biosynthesis Seminar to be held in Japan took place in June 1994 at a remote private conference center in Shizuoka Prefecture, about 25 miles north of Susono City, in plain sight of Mount Fuji. The hosts for the Susono meeting were Prof Haruo Seto and Prof Katsumi Kakinuma of Tokyo Institute of Technology. A significant fraction of the talks focused on the emerging revolution in the use of molecular genetics and recombinant DNA to discover and exploit biosynthetic pathways, including the recently discovered modular polyketide synthases, as well as the exploitation of these new methods to generate significant quantities of purified biosynthetic enzymes. The meeting was once again notable for the excellent personal and scientific interactions among all the participants. There was one amusing glitch, which was no doubt my fault. Before the meeting, several of the American participants had asked me how much money, American or Japanese, they should bring with them. I reassured them that Japan was more advanced in many regards than the US and that they could count on using a credit card anywhere they went. As it turned out, that might have been true almost anywhere, but not at the conference center where we were all staying, which accepted only Japanese yen-in cash. As a consequence, about half the American participants suddenly found they had no money with which to pay for their food and lodging expenses and no access to an ATM. Fortunately, Haruo Seto was able to arrange for his wife to wire him the equivalent of more than $\$ 6000$ from his personal bank account, and he thereby bailed out his cashless American guests. Brown University was managing the funds for the US participants from the NSF conference grant, and as the US organizer, I was supposed to arrange reimbursement for participant expenses. Instead of submitting hotel receipts for each US participant as planned, I realized that I would now have to ask the University to issue one very large check made out to Prof Haruo Seto in Japan. Fortunately Kakinuma-sensei had brought with him a very handy portable color printer on which he generated a highly impressive, very official looking, multicolor receipt printed in both Japanese and English that both he and Prof Seto then signed and personally stamped, and which was accepted by the business office at Brown without any question.

\section{VISITING JAPAN}

In June 1983, I made my first visit to Japan with the support of a JSPS Fellowship. My travel schedule included 3 weeks during which I gave lectures at 15 different universities and companies, from Sapporo to Hiroshima. I was impressed not just by the quality of the science underway, but by how well-prepared each host Department was for my visit. Everyone seemed to have taken the time to read my recent publications, as was clearly evident in both personal discussions and in 
the questions following my formal lectures. Each day I was welcomed at a new institute and had stimulating discussions with both faculty and research students, followed by an evening's dinner and entertainment, during which I would be escorted by a fresh Japanese drinking team. Prof Haruhisa Shirahama of Hokkaido University, whom I had known when I was a graduate student and he was a postdoc in the Corey laboratory, welcomed me to stay at his home in Sapporo, where he had lived since he was a small boy. He introduced me to breakfast with nattō (fermented soybean), a traditional hot bath in the evening and sleeping on a futon laid out on a tatami floor. Prof Shirahama's colleague, Prof Ichihara, introduced me to karaoke one evening, announcing after dinner, 'I like you. Let's go to my bar.' Karaoke ('empty orchestra') in those days did not involve large screen TV monitors with scenes of young lovers and beautiful gardens, with the words scrolling down the screen. The singer was handed a microphone and performed for an audience of perhaps four or five others while accompanied by the wordless recorded music. Following my first such karaoke evening, Prof Shirahama took me to the beautiful Jozankai Onsen (hot spring baths) north of Sapporo where I was able to evaporate the alcohol and instantly became a devotee of Onsen. In Sendai, Prof Kyozo Ogura of Tohoku University introduced me to Hoya (sea pineapple) sashimi, which Wikipedia describes as tasting something like iodine or 'rubber dipped in ammonia', but which I nonetheless liked, if only for the novelty value. In Tokyo, Prof Sankawa taught me to say 'Tsugi no-sureido, dozo' (next slide, please), a phrase that has lost its utility with the widespread use of Power Point. I was given a Hanko stamp, with a Kanji version of my name 'Ken', 賢meaning 'Wise', and was introduced to audiences at the University of Tokyo as a 'Henna gaijin'-a 'strange stranger'. I met many former laboratory mates from my days in the Corey laboratory, including Prof Kazuo Achiwa in Shizuoka, Prof Isao Kuwajima of Tokyo Insitute of Technology, Profs Hisashi Yamamoto and Ryoji Noyori in Nagoya, Prof Sigeru Torii in Yokohama, Dr Tetsuo Hiraoka of Sankyo Pharmaceuticals, and Dr Masayuki Narisada of Shionogi \& Co., as well as many new friends from the US-Japan Seminars, including Prof Shigeo Nozoe in Sendai, who had sponsored my JSPS application, Prof Seto and Prof Yutaka Ebizuka in Tokyo, Prof Kakinuma, and Prof Takayuki Suga of Hiroshima University, in addition to my former postdoc, Dr Akio Saito, of Kinki University. Prof Shin-ichi Ueda of Kyoto University generously took the time to introduce me to Kyoto, one of the most enchanting cities in the world, and patiently explained about Japanese language, customs, food, history, and culture, in addition to sharing his expertise in botany and enthusiasm for running.

During my JSPS tour, I visited the Kitasato Institute and met Prof Satoshi Ōmura for the first time. Prof Ōmura introduced me to the members of his research laboratory and welcomed me to his home. We had discussions about many biosynthetic topics of common interest, including of course avermectin, which had been discovered in his laboratory, a finding that has been of enormous benefit to mankind and for which he was awarded the 2015 Nobel Prize in Physiology or Medicine, to the great delight of his numerous friends and admirers around the world. Over the years, Prof Ōmura has been an unusually generous host on my several visits back to Kitasato, on one occasion kindly taking me on a personal tour of Hakone and his native Yamanashi Prefecture. In July 2005, following the Max Tishler Symposium and the celebration of Prof Ōmura's 70th birthday, he graciously led the invited speakers on a 2-day tour of art museums in Hakone and the Tokyo region.

I had the privilege of returning to Japan for international meetings, seminars and university lectures on more than 10 occasions, during which I have always been warmly welcomed and been able to share science and other mutual interests with my Japanese colleagues. Several of my former postdocs have become scientific leaders in Japan, including Prof Hideaki Oikawa of Hokkaido University, whom I first met in 1983 when he was a graduate student in Sapporo, Prof Hiroshi Noguchi at Shizuoka University, and Prof Fumitaka Kudo at Tokyo Institute of Technology.

During my 1983 visit, I also first met Dr Morimasa Yagisawa, the Managing Editor of the Journal of Antibiotics. That same year I joined the Editorial Board, on which I have had the honor of serving for more than 30 years. From 2006-2012 I shared the duties of Section Editor for natural product biosynthesis with Prof Haruo Ikeda. My laboratory has published more than a dozen papers in Journal of Antibiotics, covering our studies of both terpenoid and polyketide biosynthesis. ${ }^{63-67}$

\section{SABBATICAL AT THE UNIVERSITY OF CAMBRIDGE AND THE JOHN INNES CENTRE}

In 1989, after 6 years as Chair of the Brown Chemistry Department, I spent a 1-year sabbatical leave at the University of Cambridge. My host was Dr Chris Abell, who had been a postdoc in my laboratory in 1982-1983 before returning to a faculty position in the Department of Chemistry in Cambridge. Chris, who is now Professor in Biological Chemistry, recently also became Pro-Vice-Chancellor for Research. My family and I lived in a historic house on the west side of Cambridge that had originally been built for Charles Darwin's granddaughter, the poet Frances Darwin Cornford. As a Visiting Fellow in Christ's College I was able to experience a bit of traditional College life and to meet faculty from many other academic disciplines. In the Chemistry Department, while managing my Brown research group long distance, I gave a month-long series of graduate lectures on natural product biosynthesis. I also attended Chris's joint research meetings with the groups of Finian Leeper and Jim Staunton. Prof Battersby kindly invited me to take part in his biweekly laboratory meetings on corrin and porphyrin biosynthesis. With Chris and Finian, I learned to play snooker, which I am still very bad at, and to enjoy British ale, which I am much better at.

During the 1980s, it had become evident to me and many others in the field that further progress in the elucidation of natural product biosynthetic pathways and the characterization of the key enzymes would require the application of newly developed recombinant DNA and molecular genetic techniques. Prof David Hopwood's laboratory at the John Innes Institute in Norwich, UK was widely recognized as the world's leading center for the study of Streptomyces genetics and had in fact become a Mecca for many biosynthetic investigators. I arranged with David to make the pilgrimage as well, and from January to June 1990 I commuted from Cambridge to Norwich three days a week in order to work in the laboratory there. The environment in the Hopwood laboratory was extraordinary. I isolated Streptomyces DNA for the first time under the instruction of Dr David Sherman, then a postdoc in the Hopwood group, and now Professor at the University of Michigan. Steve Gould was there on sabbatical from Oregon State, and Dr Chaitan Khosla had just arrived fresh from his $\mathrm{PhD}$. at Cal Tech to begin his two-year postdoc. Dr Tobias Kieser, a senior member of the Hopwood laboratory, was an endless source of detailed information and technical advice. Toby and I would often go running at lunchtime around the neighboring University of East Anglia campus. I made the most of these $1 \mathrm{~h}$ jaunts, peppering him with endless questions about microbial genetics, plasmid preps and cloning strategies. Besides not wanting to waste a minute, I also hoped that by making him talk I could manage to keep breathing and stay up 
with him as he sped along the running path. In the laboratory I entertained David Hopwood with anecdotes and jokes, and I amused Chaitan with my laboratory misadventures. In the end, my experience in Norwich opened up an entirely new scientific world to me and completely altered my approach to the study of natural product biosynthesis.

\section{ENZYMOLOGY AND MOLECULAR GENETICS OF NATURAL PRODUCT BIOSYNTHESIS}

In the early 1990s, I was very fortunate to develop a fruitful collaboration with Dr Thomas M Hohn of the mycotoxins research group at the US Department of Agriculture laboratories in Peoria, IL. Hohn had reported the first purification of two fungal sesquiterpene synthases, trichodiene synthase from Fusarium sporotrichioides and aristolochene synthase from Penicillium roquefortii. ${ }^{68,69} \mathrm{He}$ then identified the structural genes for each of these two enzymes, becoming the first to clone any terpene synthase. ${ }^{70,71} \mathrm{Zhen} \mathrm{Wu}$, a graduate student in my laboratory, now with Roche Biosciences in Shanghai, then overexpressed both the trichodiene and aristolochene synthases in Escherichia coli. ${ }^{72,73}$ Jae-Kyung Sohng, another graduate student who is now Professor at Sun Moon University in Korea, purified pentalenene synthase from Streptomyces exfoliatus, which allowed us within two years to clone and overexpress the corresponding pentalenene synthase structural gene. ${ }^{74}$ Using site-directed mutagenesis of presumptive active site residues, Qun Xue (now CEO of CANbridge Life Sciences) discovered that mutants of trichodiene synthase produce mixtures of aberrant cyclization products that result from derailment or diversion of the normally cryptic, enzyme-bound cationic cyclization intermediates (Figure 10). ${ }^{75}$ Analysis of the anomalous products of many other terpene synthase mutants has since provided invaluable mechanistic insights into the multistep cyclization cascades of a wide variety of terpene synthases. ${ }^{76}$

Although I originally had thought of cell-free systems as merely a convenient tool for getting rid of the cell wall, with experience I learned to think in more biochemical terms. We now talked of substrates rather than precursors, incubations rather than feeding experiments, and kinetic parameters rather than incorporation efficiency. The study of biosynthetic transformations soon took its place as a cutting-edge branch of mechanistic enzymology,

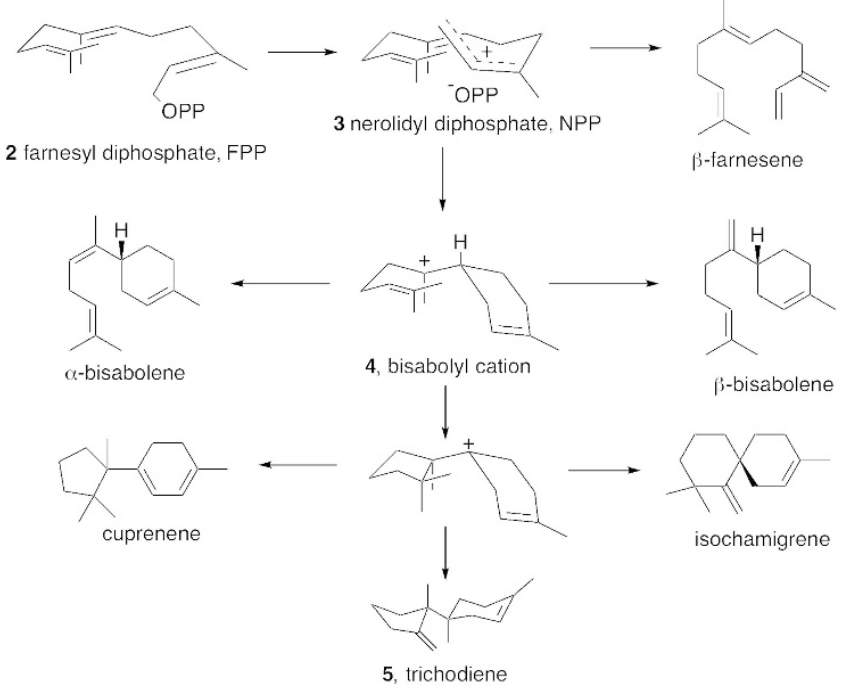

Figure 10 Formation of aberrant sesquiterpene products by abortive cyclization of FPP catalyzed by a mutant trichodiene synthase. significantly expanding the range of known biochemical reactions and mechanisms. In my own mind, instead of defining an enzyme primarily by the details of the chemical reaction that it catalyzed, I became equally interested in the protein itself and in understanding the structural basis for its intrinsic catalytic activity.

By 1995, with several robust terpene synthase expression systems in hand but knowing nothing whatsoever about the overall protein structures or any details of the active sites, we began a now 20-year collaboration with Prof David W Christianson, a protein crystallographer from the University of Pennsylvania. The first fruit of our joint efforts was the determination of the molecular structure of pentalenene synthase (Figure 11a), ${ }^{77}$ which was published in Science in 1997 along with the independent report from Prof Joseph Noel (Salk Institute) and Prof Joseph Chappell (University of Kentucky) of their determination of the structure of the tobacco sesquiterpene cyclase, epi-aristolochene synthase. ${ }^{78}$ Although the two proteins have little sequence similarity and cyclize FPP to entirely different sesquiterpenes, they share an all $\alpha$-helical fold and a highly conserved pair of $\mathrm{Mg}^{2+}$-binding domains that have a vital role in binding and activation of the allylic diphosphate substrate. These first structures were followed shortly thereafter by those of trichodiene synthase ${ }^{79}$ and aristolochene synthase (Figure 11b), ${ }^{80,81}$ In collaboration with Rod Croteau, David's laboratory also solved the crystal structure of the monoterpene synthase, bornyl diphosphate synthase. ${ }^{82}$ These studies confirmed the universal all-helical fold of the sesquiterpene and monoterpene synthases, and have provided detailed pictures of the organization of the active sites of these remarkable, synthetically versatile cyclases. ${ }^{76,83-86}$

Complementing and enriching these studies, Prof Dean J Tantillo (U. C. Davis) has deepened the understanding of the mechanisms and energetics of terpene cyclization reactions through detailed quantum chemical calculations of the reaction pathways linking carbocationic intermediates and transition state structures for a wide variety of terpene synthase-catalyzed reactions. ${ }^{87-91}$

In spite of the substantial progress in cloning terpene synthases, the search for additional terpene synthase genes was seriously hindered by the exceptionally low levels of mutual sequence similarity among known terpene synthases, thus thwarting the routine application of homology-based cloning methods to this class of microbial proteins. It occurred to me that it might be possible to find and then biochemically characterize microbial terpene synthases by using known terpene synthase sequences to query the then newly emerging microbial genome sequences. Indeed, even before the full genome sequence of Streptomyces coelicolor had been completed, the partially processed data were available on the Sanger Centre website. Using this bioinformatics approach we identified a $2.2-\mathrm{kb}$ sequence that encoded a predicted protein of 726 amino acids with modest $40 \%$ levels of similarity in both its N-terminal and C-terminal halves to pentalenene synthase. Dr Rory Watt (now at the University of Hong Kong) then expressed the Cyc2 protein and established that it catalyzed cyclization of FPP to the monocyclic sesquiterpene alcohol $(4 S, 7 R)$ germacradienol (17), an activity that he also showed was due exclusively to the N-terminal half of the protein (Figure 12). ${ }^{92}$ This discovery, however interesting, might have remained only a curiosity, had not Keith Chater, Greg Challis and their collaborators at the John Innes, using their newly developed method for generating directed in-frame gene knockouts in Streptomyces, discovered simultaneously that the same $2.3-\mathrm{kb}$ gene is essential to the biosynthesis of the well-known odoriferous compound geosmin (18), a volatile degraded sesquiterpene produced by all Streptomyces that is responsible for the universally recognized odor of moist soil..$^{93}$ Two graduate students in 

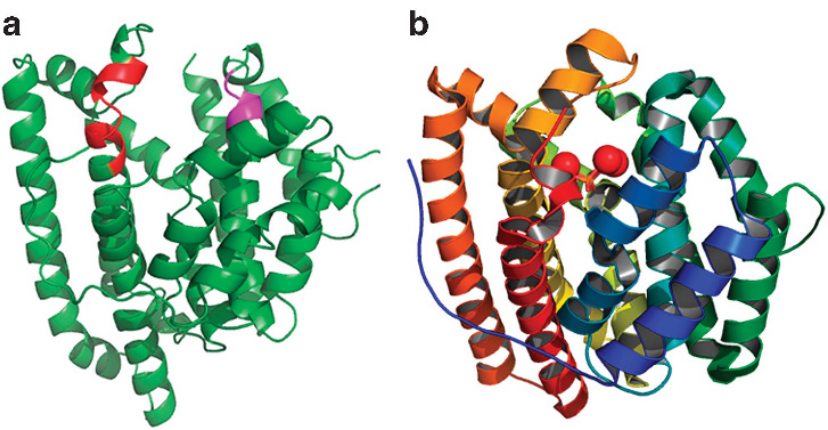

Figure 11 Sesquiterpene synthase structures. (a) Pentalenene synthase from Streptomyces exfoliatus. The conserved DDLFD and NDIASLEKE $\mathrm{Mg}^{2+}$-binding domains are shown in magenta and red, respectively. (b) Aspergillus terreus aristolochene synthase with bound $\mathrm{PP}_{\mathrm{i}}-\left(\mathrm{Mg}^{2+}\right)_{3}$ and closed active site lid (orange).

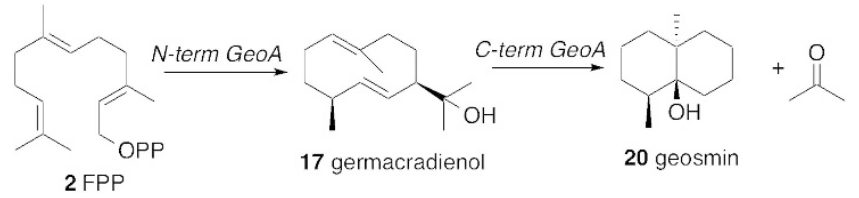

Figure 12 Cyclization of FPP to germacradienol (17) and conversion to geosmin (18) and acetone by the bifunctional terpene synthase GeoA.

my laboratory, Xiaofei He (now at Shanghai Jiaotong University) and Jiaoyang Jiang (now an Assistant Professor at the School of Pharmacy at the University of Wisconsin), then made the unexpected discovery that germacradienol synthase is in fact a bifunctional geosmin synthase enzyme that converts FPP all the way to geosmin, with the C-terminal domain catalyzing an unprecedented cyclization-fragmentation of the initially formed germacradienol (Figure 12). ${ }^{94,95}$ Geosmin synthase also turns out to be an unusually highly conserved protein that is found in essentially every one of the dozens of Streptomyces genome sequences reported to date, as well as the genomes of a wide variety of Myxobacteria and cyanobacteria. Curiously, the actual biological function of geosmin remains an unsolved puzzle.

Before the first results of our geosmin research had been published, Prof Ömura and his senior collaborator, Prof Haruo Ikeda, wrote to tell me that they had completed sequencing the genome of the avermectin producer $S$. avermitilis. ${ }^{96}$ They inquired whether I would be interested in collaborating to assign the actual biochemical function of the four putative terpene synthase genes that were harbored in the $S$. avermitilis genome. In fact, it was evident that one of these S. avermitilis terpene synthase genes was a geosmin synthase, ${ }^{66}$ while a second corresponded to epi-isozizaene synthase whose function in S. coelicolor we had just established. ${ }^{97,98}$ A third gene was subsequently shown by Dr Wayne Chou in my laboratory to control the cyclization of FPP to a previously unknown sesquiterpene alcohol that we named avermitilol..$^{99}$ Of special interest was the presence in S. avermitilis of a presumptive pentalenene synthase located within a 13.4-kb cluster of 13 unidirectionally transcribed genes. ${ }^{100}$ Although it soon became evident that $S$. avermitilis itself does not produce pentalenolactone, but instead an isomeric metabolite that we named neopentalenolactone, working closely together our two laboratories were able to determine the function of all the neopentalenolactone biosynthetic genes in the S. avermitilis cluster. Two postdocs in my laboratory, Dr Myung-ji Seo (now an Assistant Professor at Incheon National University in Korea) and Dr Dongqing Zhu (currently Assistant Professor in the Key
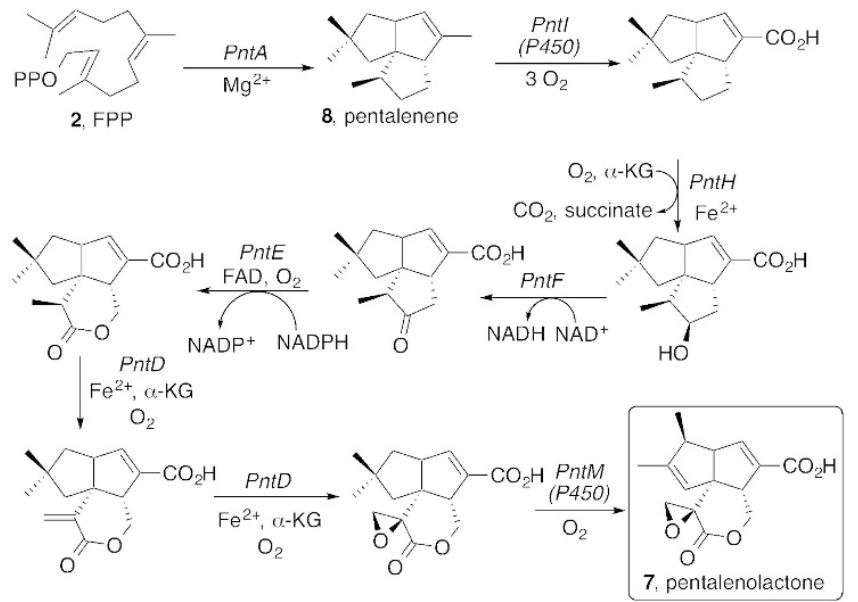

Figure 13 Cyclization of FPP (2) to pentalenene (8) and oxidative conversion to pentalenolactone (7).

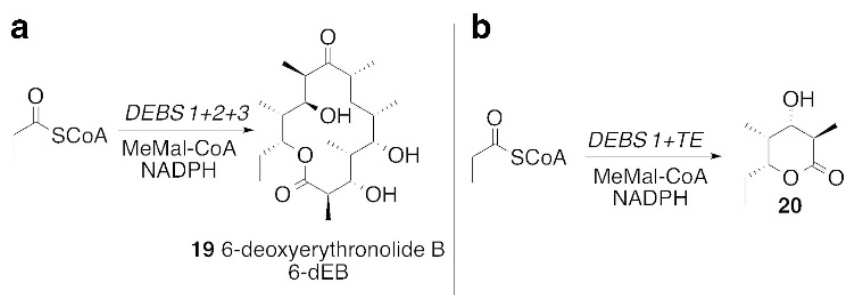

Figure 14 Enzyme-catalyzed formation of polyketides. (a) Conversion of propionyl-CoA, methylmalonyl-CoA and NADPH to 6-deoxyerythronolide B $(19,6 \mathrm{dEB})$ by recombinant DEBS1, DEBS2 and DEBS3. (b) Conversion of propionyl-CoA, methylmalonyl-CoA and NADPH to triketide lactone 20 by DEBS $1+\mathrm{TE}$.

Laboratory of Combinatorial Biosynthesis at Wuhan University in China), then isolated and sequenced the authentic pentalenolactone biosynthetic gene clusters of both S. exfoliatus and S. arenae, and then fully characterized each of the encoded enzymes, again in close collaboration with Prof Ikeda and his coworkers (Figure 13). ${ }^{101,102}$

In the meantime, beginning in 1990, research in the field of polyketide biosynthesis had taken a revolutionary turn when Prof Peter Leadlay in Cambridge and Dr Leonard Katz at Abbott Laboratories independently determined the full sequence of the 30-kb biosynthetic gene cluster for the 6-deoxyerythronolide B (19) synthase (DEBS) from Saccharopolyspora erythraea. ${ }^{103-105}$ This dramatic discovery of the modular organization of the polyketide synthases (PKSs) resulted in a true paradigm shift in the study of natural product biosynthesis, in which sequence data became the starting point for the discovery of new biochemical reactions and natural product biosynthetic pathways. Each PKS module houses the necessary catalytic domains to support a single round of polyketide chain elongation and functional group modification, with the resultant product being passed to the appropriate downstream module for a successive round of chain elongation and modification, followed ultimately by release of the mature, full-length polyketide by a dedicated thioesterase domain appended to the C-terminus of the furthest downstream module.

In 1994, Chaitan Khosla, who 2 years earlier had joined the faculty of the Department of Chemical Engineering at Stanford, described the cloning and heterologous expression in S. coelicolor of the entire DEBS gene cluster. ${ }^{106}$ Shortly thereafter, Chaitan told me that they had also 
expressed DEBS1 alone in S. coelicolor, resulting in the production of a compound that they had tentatively identified as the predicted triketide lactone $\mathbf{2 0}$ generated by DEBS modules 1 and 2 (Figure 14). As it turned out, we were able to provide him with an authentic sample of this same triketide lactone, which we had already encountered as an unwanted side product of our many unsuccessful attempts to incorporate the corresponding acyclic triketide-SNAC ester intermediate into erythromycin. ${ }^{107}$ Thus began our extremely close and highly productive collaboration of more than 20 years. Within the first 6 months our groups achieved the first in vitro enzyme-catalyzed synthesis of 6-deoxyerythronolide B (19) from propionyl-CoA, methylmalonyl-CoA, and NADPH using a mixture of DEBS1, 2, and 3 expressed from S. coelicolor (Figure 14a). ${ }^{108}$ We also described the enzymatic formation of the triketide lactone (20) by recombinant DEBS1+TE alone, a chimeric protein carrying the natural DEBS thioesterase (TE) domain from module 6 fused to the C-terminus of module 2 in order to facilitate release of the triketide and permit multiple catalytic turnovers (Figure 14b). Over the following years, Chaitan and his coworkers developed numerous powerful methods for the production and isolation of active individual PKS modules and individual recombinant PKS domains, first from S. coelicolor and then from E. coli. ${ }^{109}$ Together our groups have used these systems to establish the substrate specificity and stereochemistry of numerous PKS domains, as well as the key protein structural, biochemical, and stereochemical features that determine the highfidelity programming of complex modular polyketides. ${ }^{10-118}$ For example, we have recently shown that KR domains are responsible for controlling the stereochemistry of not only the reduced hydroxyls but also the adjacent methyl substituents of 2-methyl-3-hydroxyacyl$\mathrm{ACP}$ intermediates and also established that redox inactive $\mathrm{KR}$ domains harbor an intrinsic epimerase activity (Figure 15). ${ }^{119-124}$ A coherent, well-supported picture has emerged in which the ordered processing of pathway intermediates has been shown to involve a complex balance of specific protein-substrate and protein-protein interactions. Very recently, a novel turnstile mechanism has been shown to have a key role in the intrinsic vectorial processing of polyketide chain elongation intermediates by modular assembly lines. ${ }^{125}$

Complementing these studies, we have also investigated late stage reactions in polyketide biosynthesis. For eample, we have characterized two cytochrome P450s that modify the originally formed macrolactone, the erythromycin C-12 hydroxylase, EryK (Ralph Lambalot, now at ABBVie Pharmaceuticals) $)^{126}$ and the analogous PicK hydroxylase of methymycin/pikromycin biosynthesis (Dr Edmund Graziani, now at Pfizer). ${ }^{127,128}$

Our studies of PKS enzymology have been enhanced and broadened by our collaboration with Prof Adrian Keatinge-Clay, a crystallographer from the University of Texas, with remarkably deep insights into the relationship between $\mathrm{KR}$ stereochemistry and function. Adrian and his students have solved the structures of a wide variety of PKS domains, with particular attention to the protein structural basis of ketoreductase (KR) and dehydratase stereospecificity. ${ }^{129-133}$

Chaitan and I began to have periodic joint group meetings which were soon expanded to include annual summer meetings with the research groups of Prof Chris Walsh of Harvard Medical School and Prof Mohamed Marahiel of the University of Marburg, whose laboratories were at the forefront of the study of the closely related non-ribosomal peptide synthetases. These meetings allowed invaluable exchanges of information and advice and gave the research students all four laboratories a chance to get to know their counterparts.

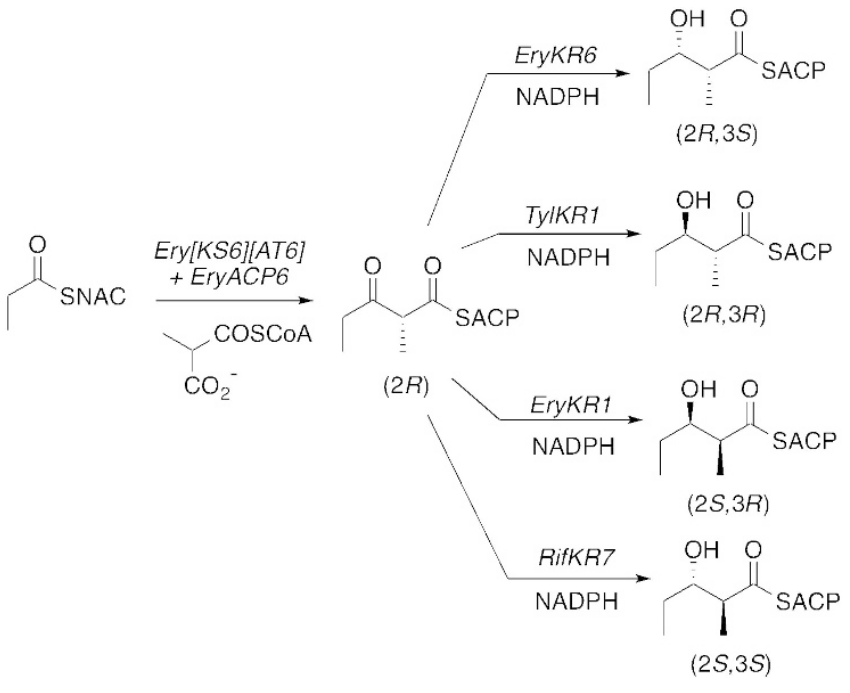

Figure 15 Stereospecific reduction of (2R)-2-methyl-3-ketopentanoyl-ACP by recombinant ketoreductase (KR) domains: EryKR6, from module 6 of the $6 \mathrm{dEB}$ synthase (DEBS); TylKR1, from module 1 of the tylactone synthase; EryKR1, from DEBS module 1; RifKR7, from module 7 of the rifamycin PKS. The (2R)-2-methyl-3-ketopentanoyl-ACP substrate is generated in situ by a reconstituted mixture of dissected PKS domains, Ery[KS6][AT6] (ketosynthase-acyl transferase didomain) and EryACP6 are both from DEBS module 6.

With the coming of the genomic era, the study of natural product biosynthesis has undergone a revolution in both methodology and practice. In place of the classical bottom up approach in which one first characterizes a biochemical transformation, then isolates and purifies the responsible enzyme, and finally identifies the relevant gene, today almost every inquiry involves the reverse, top to bottom gene-based strategy. Thus the starting point is often a genome sequence which can be bioinformatically mined to detect known or possibly new biochemical activities or to identify presumptive biosynthetic gene clusters. The assignment of the actual biochemical function of the encoded protein, or indeed the determination of the structure and function of the cryptic natural product whose biosynthesis is encoded in the genomic sequence, has now become a major experimental challenge.

During the past 45 years, I have been fortunate to be able to participate in the exciting growth and development of natural product biosynthetic studies and to contribute to the understanding of the fascinating underlying biochemistry. These efforts have been made possible by an exceptionally dedicated and talented group of postdoctoral, graduate, and undergraduate researchers. I have also benefited enormously from the generosity, enthusiasm, and friendship of a remarkable group of scientific collaborators that has taken our mutual scientific efforts to levels that I never could have aspired to achieve on my own. I express my sincere gratitude to all who have given me the opportunity to make this scientific journey and to contribute to our shared understanding of how Nature does organic chemistry.

\section{CONFLICT OF INTEREST}

The author declares no conflict of interest.

David E Cane

Department of Chemistry, Box H, Brown University, Providence, RI, USA

E-mail: David_Cane@brown.edu 
1 Kulkarni, K. S. et al. Structure of $\beta$-bergamotene. Tetrahedron Lett. 4, 505-511 (1963).

2 Corey, E. J., Cane, D. E. \& Libit, L. The Synthesis of Racemic $\alpha$-trans and ß-trans-Bergamotene. J. Am. Chem. Soc. 93, 7016-7021 (1971).

3 Brechbuehler-Bader, S. Coscia, C. J, Loew, P. Von Szczepanski, C. \& Arigoni, D. Chemistry and biosynthesis of loganin. Chem. Commun. 136-137 (1968).

4 Loew, P. \& Arigoni, D. Biological conversion of loganin into indole alkaloids. Chem. Commun. 137-138 (1968).

5 Battersby, A. R., Kapil, R. S., Martin, J. A. \& Mo, L. Loganin as precursor of the indole alkaloids. Chem. Commun. 133-134 (1968).

6 Battersby, A. R., Kapil, R. S. \& Southgate, R. Structure, stereochemistry, and biosynthesis of loganin. Chem. Commun. 131-133 (1968).

7 Money, T., Wright, I. G., McCapra, F., Hall, E. S. \& Scott, A. I. Biosynthesis of indole alkaloids. Vindoline. J. Am. Chem. Soc. 90, 4144-4150 (1968).

8 Arigoni, D., Cane, D. E., Mueller, B. \& Tamm, C. The mode of incorporation of farnesyl pyrophosphate into verrucarol. Helv. Chim. Acta 56, 2946-2949 (1973).

9 Rohr, M. Zur Biogenese des Avocettins Diss. Nr. 5212 (PhD thesis, ETH, Zürich, 1973).

10 Ruzicka, L., Eschenmoser, A. \& Heusser, H. The isoprene rule and the biogenesis of terpenic compounds. Experientia 9, 357-396 (1953)

11 Cane, D. E. et al. Trichodiene biosynthesis and the stereochemistry of the enzymatic cyclization of farnesyl pyrophosphate. Bioorg. Chem. 13, 246-265 (1985).

12 Cane, D. E. \& Ha, H. J. Trichodiene biosynthesis and the enzymatic cyclization of nerolidyl pyrophosphate. J. Am. Chem. Soc. 108, 3097-3099 (1986).

13 Cane, D. E., Iyengar, R. \& Shiao, M.-S. Cyclonerodiol biosynthesis and the stereochemistry of the conversion of farnesyl to nerolidyl pyrophosphate. J. Am. Chem. Soc. 100, 7122-7125 (1978).

14 Cane, D. E., lyengar, R. \& Shiao, M.-S. Cyclonerodiol biosynthesis and the enzymic conversion of farnesyl to nerolidyl pyrophosphate. J. Am. Chem. Soc. 103, 914-931 (1981)

15 Cane, D. E. \& Levin, R. H. Application of carbon-13 magnetic resonance to isoprenoid biosynthesis. II. Ovalicin and the use of doubly labeled mevalonate. J. Am. Chem. Soc. 98, 1183-1188 (1976)

16 Cane, D. E. \& Buchwald, S. L. Application of deuterium magnetic resonance to biosynthetic studies. 1. Biosynthesis of ovalicin. J. Am. Chem. Soc. 99, 6132-6134 (1977)

17 Cane, D. E. \& King, G. G. S. The biosynthesis of ovalicin: Isolation of $\beta$-transbergamotene. Tetrahedron Lett. 17, 4737-4740 (1976).

18 Lin, H. C. et al. The fumagillin biosynthetic gene cluster in Aspergillus fumigatus encodes a cryptic terpene cyclase involved in the formation of $\beta$-trans-bergamotene. J. Am. Chem. Soc. 135, 4616-4619 (2013).

19 Takeuchi, S., Ogawa, Y. \& Yonehara, H. The structure of pentalenolactone (PA-132). Tetrahedron Lett. 2737-2740 (1969).

20 Martin, D. G., Slomp, G., Mizsak, S., Duchamp, D. J. \& Chidester, C. G. The structure and absolute configuration of pentalenolactone (PA 132). Tetrahedron Lett. 4901-4904 (1970).

21 Cane, D. E., Rossi, T. \& Pachlatko, J. P. The biosynthesis of pentalenolactone. Tetrahedron Lett. 3639-3642 (1979).

22 Seto, H. \& Yonehara, H. Studies on the biosynthesis of pentalenolactone. III. Isolation of a biosynthetic intermediate hydrocarbon, pentalenene. J. Antibiot. 33, 92-93 (1980)

23 Schwarz, M., Arigoni, D. in Comprehensive Natural Products Chemistry: Isoprenoids Including Carotenoids and Steroids Vol. 2 (ed. Cane D. E.) 367-400 (Elsevier, 1999).

24 Rohmer, M. in Comprehensive Natural Products Chemistry: Isoprenoids Including Carotenoids and Steroids Vol. 2 (ed Cane D. E.) 45-67 (Elsevier, 1999).

25 Orihara, N., Kuzuyama, T., Takahashi, S., Furihata, K. \& Seto, H. Studies on the biosynthesis of terpenoid compounds produced by Actinomycetes. 3. Biosynthesis of the isoprenoid side chain of novobiocin via the non-mevalonate pathway in Streptomyces niveus. J. Antibiot. 51, 676-678 (1998).

26 Cane, D. E. in Comprehensive Natural Products Chemistry: Isoprenoids Including Carotenoids and Steroids Vol. 2 (ed. Cane D. E.) 155-200 (Elsevier, 1999).

27 Cane, D. E. \& Pargellis, C. Partial purification and characterization of pentalenene synthase. Arch. Biochem. Biophys. 254, 421-429 (1987).

28 Harrison, P. H. M., Oliver, J. S. \& Cane, D. E. Pentalenene biosynthesis and the enzymic cyclization of farnesyl pyrophosphate. Inversion at C-1 during 11-memberedring formation. J. Am. Chem. Soc. 110, 5922-5923 (1988).

29 Cane, D. E. et al. Aristolochene biosynthesis and enzymatic cyclization of farnesyl pyrophosphate. J. Am. Chem. Soc. 111, 8914-8916 (1989).

30 Cane, D. E., Prabhakaran, P. C., Oliver, J. S. \& Mcllwaine, D. B. Aristolochene biosynthesis. Stereochemistry of the deprotonation steps in the enzymatic cyclization of farnesyl pyrophosphate. J. Am. Chem. Soc. 112, 3209-3210 (1990).

31 Cane, D. E., Mcllwaine, D. B. \& Harrison, P. H. M. Bergamotene biosynthesis and the enzymatic cyclization of farnesyl pyrophosphate. J. Am. Chem. Soc. 111, 1152-1153 (1989).

32 Croteau, R. \& Karp, F. Demonstration of a cyclic pyrophosphate intermediate in the enzymatic conversion of neryl pyrophosphate to borneol. Arch. Biochem. Biophys. 184, 77-86 (1977).

33 Croteau, R. \& Karp, F. Biosynthesis of monoterpenes: partial purification and characterization of 1,8-cineole synthetase from Salvia officinalis. Arch. Biochem. Biophys. 179, 257-265 (1977).

34 Croteau, R., Felton, M. \& Ronald, R. C. Biosynthesis of monoterpenes: preliminary characterization of l-endo-fenchol synthetase from fennel (Foeniculum vulgare) and evidence that no free intermediate is involved in the cyclization of geranyl pyrophosphate to the rearranged product. Arch. Biochem. Biophys. 200, 534-546 (1980)

35 Cane, D. E., Saito, A., Croteau, R., Shaskus, J. \& Felton, M. Enzymic cyclization of geranyl pyrophosphate to bornyl pyrophosphate. Role of the pyrophosphate moiety. J. Am. Chem. Soc. 104, 5831-5833 (1982).

36 Croteau, R. B. et al. Mechanism of the pyrophosphate migration in the enzymic cyclization of geranyl and linalyl pyrophosphates to $(+)$ - and (-)-bornyl pyrophosphates. Biochemistry 24, 7077-7085 (1985)

37 Cane, D. E. Brushes with sage. Arch. Biochem. Biophys. 448, 117-122 (2006).

38 Croteau, R. Biosynthesis and catabolism of monoterpenoids. Chem. Rev. 87, 929-954 (1987)

39 Celmer, W. D. A configurational model for macrolide antibiotics. J. Am. Chem. Soc. 87, 1801-1802 (1965)

40 Celmer, W. D. Stereochemical problems in macrolide antibiotics. Pure Appl. Chem. 28, 413-453 (1971).

41 Cane, D. E., Hasler, H. \& Liang, T.-C. Macrolide biosynthesis. Origin of the oxygen atoms in the erythromycins. J. Am. Chem. Soc. 103, 5960-5962 (1981).

42 Cane, D. E. \& Yang, C.-C. The biosynthetic origin of the carbon skeleton and oxygen atoms of nargenicin A1. J. Am. Chem. Soc. 106, 784-787 (1984).

43 Cane, D. E. \& Yang, C. C. Nargenicin biosynthesis: late stage oxidations and absolute configuration. J. Antibiot. 38, 423-426 (1985).

44 Cane, D. E. et al. Biosynthetic origin of the carbon skeleton and oxygen atoms of the avermectins. J. Am. Chem. Soc. 105, 4110-4112 (1983).

45 Cane, D. E., Liang, T.-C. \& Hasler, H. Polyether biosynthesis. Origin of the oxygen atoms of monensin A. J. Am. Chem. Soc. 103, 5962-5965 (1981).

46 Cane, D. E., Liang, T. C. \& Hasler, H. Polyether biosynthesis. 2. Origin of the oxygen atoms of monensin A. J. Am. Chem. Soc. 104, 7274-7281 (1982).

47 Cane, D. E., Celmer, W. D. \& Westley, J. W. A unified stereochemical model of polyether structure and biogenesis. J. Am. Chem. Soc. 105, 3594-3600 (1983).

48 Bhatt, A. et al. Accumulation of an E,E,E-triene by the monensin-producing polyketide synthase when oxidative cyclization is blocked. Angew. Chem. Int. Ed. Engl. 44, 7075-7078 (2005)

49 Gallimore, A. R. et al. Evidence for the role of the monB genes in polyether ring formation during monensin biosynthesis. Chem. Biol. 13, 453-460 (2006).

50 Shichijo, Y. et al. Epoxide hydrolase Lsd19 for polyether formation in the biosynthesis of lasalocid A: direct experimental evidence on polyene-polyepoxide hypothesis in polyether biosynthesis. J. Am. Chem. Soc. 130, 12230-12231 (2008).

51 Hotta, K. et al. Enzymatic catalysis of anti-Baldwin ring closure in polyether biosynthesis. Nature 483, 355-358 (2012)

52 Cane, D. E. \& Yang, C.-C. Macrolide biosynthesis. 4. Intact Incorporation of a chain elongation intermediate into erythromycin. J. Am. Chem. Soc. 109, 1255-1257 (1987).

53 Yue, S., Duncan, J. S., Yamamoto, Y. \& Hutchinson, C. R. Macrolide biosynthesis. Tylactone formation involves the processive addition of three carbon units. J. Am. Chem. Soc. 109, 1253-1255 (1987).

54 Cane, D. E. \& Ott, W. R. Macrolide biosynthesis. 5. Intact incorporation of a chain-elongation intermediate into nargenicin. J. Am. Chem. Soc. 110, 4840-4841 (1988).

55 Cane, D. E., Tan, W. \& Ott, W. R. Nargenicin biosynthesis. Incorporation of polyketide chain elongation intermediates and support for a proposed intramolecular Diels-Alder cyclization. J. Am. Chem. Soc. 115, 527-535 (1993).

56 Cane, D. E., Lambalot, R. H., Prabhakaran, P. C. \& Ott, W. R. Macrolide biosynthesis. 7. Incorporation of polyketide chain elongation intermediates into methymycin. J. Am. Chem. Soc. 115, 522-526 (1993).

57 Seto, H., Cary, L. W. \& Tanabe, M. Utilization of carbon-13-carbon-13 coupling in structural and biosynthetic studies. Fourier transform carbon-13 nuclear magnetic resonance spectrum of mollisin. J. Chem. Soc. Chem. Commun. 867-868 (1973)

58 Tanabe, M. \& Suzuki, K. T. Biosynthetic studies with carbon-13. Incorporation pattern of $1,2-{ }^{13} \mathrm{C}$-acetate into the fungal sesquiterpene ovalicin. Tetrahedron Lett. $\mathbf{1 5}$, 4417-4420 (1974).

59 Nozoe, S., Kobayashi, H. \& Morisaki, N. Isolation of $\beta$-trans-bergamotene from Aspergillus fumigatus, a fumagillin producing fungi. Tetrahedron Lett. 17, 4625-4626 (1976)

60 Nozoe, S. \& Machida, Y. The structures of trichodiol and trichodiene. Tetrahedron 28 5105-5111 (1972).

61 Nozoe, S., Goi, M. \& Morisaki, N. Structure of cyclonerodiol. Tetrahedron Lett. 11, 1293-1296 (1970)

62 Morikawa, K., Hirose, Y. \& Nozoe, S. Biosynthesis of germacrene-C. Tetrahedron Lett 12, 1131-1132 (1971).

63 Cane, D. E., Rawlings, B. J. \& Yang, C.-C. Isolation of $(-)-\gamma$-cadinene and aristolochene from Aspergillus terreus. J. Antibiot. 40, 1331-1334 (1987).

64 Williard, P. G., Sohng, J. K. \& Cane, D. E. The X-ray crystal structure of pentalenolactone $\mathrm{F}$ methyl ester (epi-pentalenolactone F). J. Antibiot. 41, 130-133 (1988)

65 Lambalot, R. H. \& Cane, D. E. Isolation and characterization of 10-deoxymethynolide produced by Streptomyces venezuelae. J. Antibiot. 45, 1981-1982 (1992).

66 Cane, D. E., He, X., Kobayashi, S., Omura, S. \& Ikeda, H. Geosmin biosynthesis in Streptomyces avermitilis. Molecular cloning, expression, and mechanistic study of the germacradienol/geosmin synthase. J. Antibiot. 59, 471-479 (2006).

67 Yamada, Y. et al. Novel terpenes generated by heterologous expression of bacterial terpene synthase genes in an engineered Streptomyces host. J. Antibiot. 68 385-394 (2015). 
68 Hohn, T. M. \& VanMiddlesworth, F. Purification and characterization of the sesquiterpene cyclase trichodiene synthetase from Fusarium sporotrichioides. Arch. Biochem. Biophys. 251, 756-761 (1986).

69 Hohn, T. M. \& Plattner, R. D. Purification and characterization of the sesquiterpene cyclase aristolochene synthase from Penicillium roqueforti. Arch. Biochem. Biophys. 272, 137-143 (1989).

70 Hohn, T. M. \& Beremand, P. D. Isolation and nucleotide sequence of a sesquiterpene cyclase gene from the trichothecene-producing fungus Fusarium sporotrichioides. Gene 79, 131-138 (1989).

71 Proctor, R. H. \& Hohn, T. M. Aristolochene synthase. Isolation, characterization, and bacterial expression of a sesquiterpenoid biosynthetic gene (Ari1) from Penicillium roqueforti. J. Biol. Chem. 268, 4543-4548 (1993).

72 Cane, D. E., Wu, Z., Oliver, J. S. \& Hohn, T. M. Overproduction of soluble trichodiene synthase from Fusarium sporotrichioides in Escherichia coli. Arch. Biochem. Biophys. 300, 416-422 (1993).

73 Cane, D. E., Wu, Z., Proctor, R. H. \& Hohn, T. M. Overexpression in Escherichia coli of soluble aristolochene synthase from Penicillium roqueforti. Arch. Biochem. Biophys. 304, 415-419 (1993).

74 Cane, D. E. et al. Pentalenene synthase. Purification, molecular cloning, sequencing and high-level expression in Escherichia coli of a terpenoid cyclase from Streptomyces UC5319. Biochemistry 33, 5846-5857 (1994).

75 Cane, D. E. \& Xue, Q. Trichodiene synthase. Enzymatic formation of multiple sesquiterpenes by alteration of the cyclase active site. J. Am. Chem. Soc. 118, 1563-1564 (1996).

$76 \mathrm{Li}, \mathrm{R}$. et al. Reprogramming the chemodiversity of terpenoid cyclization by remolding the active site contour of epi-isozizaene synthase. Biochemistry 53, 1155-1168 (2014).

77 Lesburg, C. A., Zhai, G., Cane, D. E. \& Christianson, D. W. Crystal structure of pentalenene synthase: mechanistic insights on terpenoid cyclization reactions in biology. Science 277, 1820-1824 (1997).

78 Starks, C. M., Back, K., Chappell, J. \& Noel, J. P. Structural basis for cyclic terpene biosynthesis by tobacco 5-epi-aristolochene synthase. Science 277, 1815-1820 (1997).

79 Rynkiewicz, M. J., Cane, D. E. \& Christianson, D. W. Structure of trichodiene synthase from Fusarium sporotrichioides provides mechanistic inferences on the terpene cyclization cascade. Proc. Natl Acad. Sci. USA 98, 13543-13548 (2001).

80 Caruthers, J. M., Kang, I., Rynkiewicz, M. J., Cane, D. E. \& Christianson, D. W. Crystal structure determination of aristolochene synthase from the blue cheese mold. Penicillium roqueforti. J. Biol. Chem. 275, 25533-25539 (2000).

81 Shishova, E. Y., Costanzo, L. D., Cane, D. E. \& Christianson, D. W. X-ray Crystal Structure of aristolochene synthase from Aspergillus terreus and evolution of templates for the cyclization of farnesyl diphosphate. Biochemistry 46, 1941-1951 (2007).

82 Whittington, D. A. et al. Bornyl diphosphate synthase: structure and strategy for carbocation manipulation by a terpenoid cyclase. Proc. Natl Acad. Sci. USA 99, 15375-15380 (2002).

83 Christianson, D. W. Structural biology and chemistry of the terpenoid cyclases. Chem. Rev. 106, 3412-3442 (2006).

84 Christianson, D. W. Unearthing the roots of the terpenome. Curr. Opin. Chem. Biol. 12, 141-150 (2008).

85 Aaron, J. A., Lin, X., Cane, D. E. \& Christianson, D. W. Structure of epi-isozizaene synthase from Streptomyces coelicolor A3(2), a platform for new terpenoid cyclization templates. Biochemistry 49, 1787-1797 (2010).

86 Koksal, M., Chou, W. K., Cane, D. E. \& Christianson, D. W. Structure of 2-methylisoborneol synthase from Streptomyces coelicolor and implications for the cyclization of a noncanonical C-methylated monoterpenoid substrate. Biochemistry 51, 3011-3020 (2012).

87 Gutta, P. \& Tantillo, D. J. Theoretical studies on farnesyl cation cyclization: pathways to pentalenene. J. Am. Chem. Soc. 128, 6172-6179 (2006).

88 Hong, Y. J. \& Tantillo, D. J. Consequences of conformational preorganization in sesquiterpene biosynthesis: Theoretical studies on the formation of the bisabolene, curcumene, ccoradiene, zizaene, cedrene, duprezianene, and sesquithuriferol sesquiterpenes. J. Am. Chem. Soc. 131, 7999-8015 (2009).

89 Tantillo, D. J. Biosynthesis via carbocations: theoretical studies on terpene formation. Nat. Prod. Rep. 28, 1035-1053 (2011).

$90 \mathrm{Zu}$, L. et al. Effect of isotopically sensitive branching on product distribution for pentalenene synthase: support for a mechanism predicted by quantum chemistry. J. Am. Chem. Soc. 134, 11369-11371 (2012).

91 Hong, Y. J. \& Tantillo, D. J. Feasibility of intramolecular proton transfers in terpene biosynthesis-guiding principles. J. Am. Chem. Soc. 137, 4134-4140 (2015).

92 Cane, D. E. \& Watt, R. M. Expression and mechanistic analysis of a germacradienol synthase from Streptomyces coelicolor implicated in geosmin biosynthesis. Proc. Natl. Acad. Sci. USA 100, 1547-1551 (2003).

93 Gust, B., Challis, G. L., Fowler, K., Kieser, T. \& Chater, K. F. PCR-targeted Streptomyces gene replacement identifies a protein domain needed for biosynthesis of the sesquiterpene soil odor geosmin. Proc. Natl. Acad. Sci. USA 100, 1541-1546 (2003).

94 Jiang, J., He, X. \& Cane, D. E. Geosmin biosynthesis. Streptomyces coelicolor germacradienol/germacrene $D$ synthase converts farnesyl diphosphate to geosmin. J. Am. Chem. Soc. 128, 8128-8129 (2006).

95 Jiang, J., He, X. \& Cane, D. E. Biosynthesis of the earthy odorant geosmin by a bifunctional Streptomyces coelicolor enzyme. Nat. Chem. Biol. 3, 711-715 (2007).
96 Omura, S. et al. Genome sequence of an industrial microorganism Streptomyces avermitilis: deducing the ability of producing secondary metabolites. Proc. Natl Acad. Sci. USA 98, 12215-12220 (2001).

97 Lin, X. \& Cane, D. E. Biosynthesis of the sesquiterpene antibiotic albaflavenone in Streptomyces coelicolor. Mechanism and stereochemistry of the enzymatic formation of epi-isozizaene. J. Am. Chem. Soc. 131, 6332-6333 (2009).

98 Takamatsu, S. et al. Characterization of a silent sesquiterpenoid biosynthetic pathway in Streptomyces avermitilis controlling epi-isozizaene and albaflavenone biosynthesis and isolation of a new oxidized epi-isozizaene metabolite. Microb. Biotechnol. 4, 184-191 (2011).

99 Chou, W. K. et al. Genome mining in Streptomyces avermitilis: cloning and characterization of SAV_76, the synthase for a new sesquiterpene, avermitilol. J. Am. Chem. Soc. 132, 8850-8851 (2010).

100 Tetzlaff, C. N. et al. A gene cluster for biosynthesis of the sesquiterpenoid antibiotic pentalenolactone in Streptomyces avermitilis. Biochemistry 45, 6179-6186 (2006).

$101 \mathrm{Seo}, \mathrm{M}$. J., Zhu, D. Endo, S. Ikeda, H. \& Cane, D. E. Genome mining in Streptomyces. Elucidation of the role of Baeyer-Villiger monooxygenases and nonheme iron-dependent dehydrogenase/oxygenases in the final steps of the biosynthesis of pentalenolactone and neopentalenolactone. Biochemistry 50, 1739-1754 (2011).

102 Zhu, D., Seo, M. J., Ikeda, H. \& Cane, D. E. Genome mining in Streptomyces. Discovery of an unprecedented P450-catalyzed oxidative rearrangement that is the final step in the biosynthesis of pentalenolactone. J. Am. Chem. Soc. 133, 2128-2131 (2011).

103 Cortes, J., Haydock, S. F., Roberts, G. A., Bevitt, D. J. \& Leadlay, P. F. An unusually large multifunctional polypeptide in the erythromycin-producing polyketide synthase of Saccharopolyspora erythraea. Nature 348, 176-178 (1990).

104 Donadio, S., Staver, M. J., Mcalpine, J. B., Swanson, S. J. \& Katz, L. Modular organization of genes required for complex polyketide biosynthesis. Science 252, 675-679 (1991).

105 Donadio, S. \& Katz, L. Organization of the enzymatic domains in the multifunctional polyketide synthase involved in erythromycin formation in Saccharopolysporaerythraea. Gene 111, 51-60 (1992).

106 Kao, C. M., Katz, L. \& Khosla, C. Engineered biosynthesis of a complete macrolactone in a heterologous host. Science 265, 509-512 (1994).

107 Kao, C. M., Luo, G., Katz, L., Cane, D. E. \& Khosla, C. Engineered biosynthesis of a triketide lactone from an incomplete modular polyketide synthase. J. Am. Chem. Soc. 116, 11612-11613 (1994).

108 Pieper, R., Luo, G. L., Cane, D. E. \& Khosla, C. Cell-free synthesis of polyketides by recombinant erythromycin polyketide synthases. Nature 378, 263-266 (1995).

109 Pieper, R., Gokhale, R. S., Luo, G., Cane, D. E. \& Khosla, C. Purification and characterization of bimodular and trimodular derivatives of the erythromycin polyketide synthase. Biochemistry 36, 1846-1851 (1997).

110 Khosla, C., Gokhale, R. S., Jacobsen, J. R. \& Cane, D. E. Tolerance and specificity of polyketide synthases. Ann. Rev. Biochem. 68, 219-253 (1999).

111 Khosla, C., Herschlag, D., Cane, D. E. \& Walsh, C. T. Assembly line polyketide synthases: mechanistic insights and unsolved problems. Biochemistry 53, 2875-2883 (2014).

112 Chuck, J. et al. Molecular recognition of diketide substrates by a $\beta$-ketoacyl-ACP synthase domain within a bimodular polyketide synthase. Chem. Biol. 4, 757-766 (1997).

$113 \mathrm{Kao}, \mathrm{C}$. M. et al. Gain of function mutagenesis of the erythromycin polyketide synthase. 2. Engineered biosynthesis of an eight-membered tetraketide lactone. J. Am. Chem. Soc. 119, 11339-11340 (1997).

$114 \mathrm{Kao}, \mathrm{C} . \mathrm{M}$. et al. Alcohol stereochemistry in polyketide backbones Is controlled by the $\beta$-ketoreductase domains of modular polyketide synthases. J. Am. Chem. Soc. 120, 2478-2479 (1998).

115 Gokhale, R. S., Tsuji, S. Y., Cane, D. E. \& Khosla, C. Dissecting and exploiting intermodular communication in polyketide synthases. Science 284, 482-485 (1999).

$116 \mathrm{Wu}$, N., Tsuji, S. Y., Cane, D. E. \& Khosla, C. Assessing the balance between protein-protein interactions and enzyme- substrate interactions in the channeling of intermediates between polyketide synthase modules. J. Am. Chem. Soc. 123, 6465-6474 (2001).

117 McPherson, M., Khosla, C. \& Cane, D. E. Erythromycin biosynthesis: the $\beta$-ketoreductase domains catalyze the stereospecific transfer of the 4-pro-S hydride of NADPH. J. Am. Chem. Soc. 120, 3267-3268 (1998).

118 Pfeifer, B. A., Admiraal, S. J., Gramajo, H., Cane, D. E. \& Khosla, C. Biosynthesis of complex polyketides in a metabolically engineered strain of $E$. coli. Science 291 , 1790-1792 (2001).

119 Castonguay, R., He, W., Chen, A. Y., Khosla, C. \& Cane, D. E. Stereospecificity of ketoreductase domains of the 6-deoxyerythronolide B synthase. J. Am. Chem. Soc. 129, 13758-13769 (2007).

120 Castonguay, R. et al. Stereospecificity of ketoreductase domains 1 and 2 of the tylactone modular polyketide synthase. J. Am. Chem. Soc. 130, 11598-11599 (2008).

121 Valenzano, C. R., Lawson, R. J., Chen, A. Y., Khosla, C. \& Cane, D. E. The biochemical basis for stereochemical control in polyketide biosynthesis. J. Am. Chem. Soc. 131, 18501-18511 (2009).

122 Garg, A., Khosla, C. \& Cane, D. E. Coupled methyl group epimerization and reduction by polyketide synthase ketoreductase domains. Ketoreductase-catalyzed equilibrium isotope exchange. J. Am. Chem. Soc. 135, 16324-16327 (2013).

123 Garg, A., Xie, X., Keatinge-Clay, A., Khosla, C. \& Cane, D. E. Elucidation of the cryptic epimerase activity of redox-inactive ketoreductase domains from modular polyketide synthases by tandem equilibrium isotope exchange. J. Am. Chem. Soc. 136, 10190-10193 (2014). 
124 Xie, X., Garg, A., Keatinge-Clay, A. T., Khosla, C. \& Cane, D. E. Epimerase and reductase activities of polyketide synthase ketoreductase domains utilize the same conserved tyrosine and serine residues. Biochemistry 55, 1179-1186 (2016).

125 Lowry, B., Li, X., Robbins, T., Cane, D. E. \& Khosla, C. A turnstile mechanism for the controlled growth of biosynthetic intermediates on assembly line polyketide synthases. ACS Cent. Sci. 2, 14-20 (2016).

126 Lambalot, R. H., Cane, D. E., Aparicio, J. J. \& Katz, L. Overproduction and characterization of the erythromycin C-12 hydroxylase, EryK. Biochemistry 34, 1858-1866 (1995).

127 Cane, D. E. \& Graziani, E. I. Methymycin biosynthesis. Isolation of P450 monooxygenase activity in a cell-free system from Streptomyces venezuelae. J. Am. Chem. Soc. 120, 2682-2683 (1998).

128 Graziani, E. I., Cane, D. E., Betlach, M. C., Kealey, J. T. \& McDaniel, R. Macrolide biosynthesis: a single cytochrome P450, PicK, is responsible for the hydroxylations that generate methymycin, neomethymycin, and picromycin in Streptomyces venezuelae. Bioorg. Med. Chem. Lett. 8, 3117-3120 (1998).

129 Keatinge-Clay, A. T. \& Stroud, R. M. The structure of a ketoreductase determines the organization of the beta-carbon processing enzymes of modular polyketide synthases. Structure 14, 737-748 (2006).

130 Keatinge-Clay, A. T. A tylosin ketoreductase reveals how chirality is determined in polyketides. Chem. Biol. 14, 898-908 (2007).

131 Zheng, J., Taylor, C. A., Piasecki, S. K. \& Keatinge-Clay, A. T. Structural and functional analysis of A-Type ketoreductases from the amphotericin modular polyketide synthase. Structure 18, 913-922 (2010).

132 Zheng, J. \& Keatinge-Clay, A. Structural and functional analysis of C2-type ketoreductases from modular polyketide synthases. J. Mol. Biol. 410, 105-117 (2011).

133 Keatinge-Clay, A. T. The structures of type I polyketide synthases. Nat. Prod. Rep. 29 1050-1073 (2012). 